\title{
Tabularia
}

TABULARIA Sources écrites des mondes normands médiévaux Guillaume de Volpiano : Fécamp et l'histoire normande | 2007

\section{Sur la dispersion de la bibliothèque bénédictine de Fécamp...}

Partie 1 : identification des prinicipales vagues de démembrement de fonds

On the dispersal of the Benedictine library at Fécamp

Part 1: identifying the main stages of the collection carve-up

\section{Stéphane Lecouteux}

\section{OpenEdition}

\section{Journals}

Édition électronique

URL : http://journals.openedition.org/tabularia/1986

DOI : 10.4000/tabularia.1986

ISSN : 1630-7364

Éditeur :

CRAHAM - Centre Michel de Boüard, Presses universitaires de Caen

\section{Référence électronique}

Stéphane Lecouteux, «Sur la dispersion de la bibliothèque bénédictine de Fécamp... », Tabularia [En ligne], Guillaume de Volpiano : Fécamp et l'histoire normande, mis en ligne le 19 avril 2007, consulté le 30 avril 2019. URL : http://journals.openedition.org/tabularia/1986 ; DOI : 10.4000/tabularia.1986 


\title{
Sur la dispersion de la bibliothèque bénédictine de Fécamp Partie 1 : identification des principales vagues de démembrement des fonds
}

\author{
On the dispersal of the Benedictine library at Fécamp \\ Part 1: identifying the main stages \\ of the collection carve-up
}

\author{
Stéphane LECOUTEUX ${ }^{1}$ \\ 23, rue Marceau Leyssieux \\ 38400 Saint-Martin d'Hères \\ lecouteux.stephmanue@wanadoo.fr
}

Résumé:

Comme de nombreuses abbayes, La Trinité de Fécamp a souffert d'une dispersion importante de ses livres entre le XVI e et le XVIII ${ }^{e}$ siècle. Si une partie de ces pertes est bien connue et explique aujourd'hui la présence de nombreux volumes dans les Bibliothèques municipales de Rouen et du Havre, aux Archives départementales de la Seine-Maritime, à la Bibliothèque nationale de France et dans les Musées de Fécamp, une autre reste plus obscure. La présente étude, qui s'intéresse principalement aux manuscrits médiévaux latins, permet de suspecter la dissémination à travers l'Europe de membra disiecta et de fragments insérés dans des recueils factices, en particulier dans les bibliothèques du Vatican, de Berne, de Leyde, de Berlin et de Paris. D'autres abbayes normandes, victimes de pillages huguenots en 1562 et 1563 , ont subi un processus de dispersion analogue.

Mots-clés: manuscrits, Bigot, de Mareste, Sarrau, Isaac Vossius, Petau, Pierre Daniel, de Coligny, Bongars, de Joyeuse, Hurault, Phillipps².

1. Je remercie Sébastien Bricout, Monique Peyrafort (Institut de Recherche et d'Histoire des Textes) et Dominique Rouet (conservateur de la Bibliothèque municipale du Havre) pour leurs remarques pertinentes, ainsi que pour la communication de plusieurs articles visant à l'amélioration de cette contribution. Ma gratitude va aussi spécialement à Marie-Pierre Laffitte (conservateur général du Département des manuscrits de la $\mathrm{BnF}$ ) pour sa disponibilité et pour la transmission de ses travaux sur les manuscrits de Mareste acquis par Colbert, ainsi qu'à Claudine Brabetz pour les vérifications réalisées sur les manuscrits conservés à la Bibliothèque municipale de Rouen. Merci enfin à Véronique Broust, à Emmanuelle Doucet-Lecouteux et au Comité de rédaction de la revue Tabularia pour la révision de mon texte.

2. Pour les personnages des $\mathrm{XVI}^{\mathrm{e}}-\mathrm{XIX}^{\mathrm{e}}$ siècles mentionnés dans cette étude, voir les ouvrages suivants: Biographie universelle ancienne et moderne (B.U.A.M.); Dictionnaire de biographie française (D.B.F.); Dictionnaire d'histoire et de géographie ecclésiastiques (D.H.G.E.); Biographisch-Bibliographisches Kirchenlexicon (B.B.K.L.); Catholicisme, hier, aujourd'hui, demain (C.H.A.D.). 
Abstract:

As with many abbeys, La Trinité at Fécamp witnessed a significant carve-up of its books between the $16^{\text {th }}$ and $18^{\text {th }}$ centuries. Part of the loss has been thoroughly investigated-many books are to be found today in the Rouen and Le Havre municipal libraries, in the Archives départementales de la Seine-Maritime, in Bibliothèque nationale de France and in the Fécamp museums. However less is known of other losses. This discussion focussing on medieval manuscripts in Latin points to the likely dissemination throughout Europe of membra disiecta and fragments inserted in inauthentic volumes, especially in the libraries at the Vatican, Bern, Leyden, Berlin and Paris. Other Norman abbeys, looted by the Huguenots in 1562 and 1563, went through a similar process of dispersal.

Keywords: Manuscripts, Bigot, de Mareste, Sarrau, Isaac Vossius, Petau, Pierre Daniel, de Coligny, Bongars, de Joyeuse, Hurault, Phillipps.

Grâce aux thèses et aux travaux de Geneviève Nortier, de François Avril et de Betty Branch, la bibliothèque de La Trinité de Fécamp et l'accroissement de ses fonds au cours du Moyen Âge sont relativement bien connus ${ }^{3}$. Nous savons en particulier que le scriptorium de l'établissement s'est montré actif quelques années avant la restauration de la discipline bénédictine par l'abbé Guillaume de Volpiano (1001-1028) au début du XI ${ }^{e}$ siècle. Cette vitalité s'est perpétuée au moins jusque dans la seconde moitié du XII e siècle, sous l'abbé Henri de Sully (11391187). Entre-temps, les abbatiats de Jean de Ravenne (1028-1078) et de Roger d'Argences (1108-1139) ont constitué deux périodes de renouveau et de prospérité pour le scriptorium, qui a donc connu une double apogée artistique et culturelle au cours de son histoire ${ }^{4}$. Premier monastère réformé de Normandie après l'an Mil, Fécamp a indéniablement marqué de son empreinte plusieurs communautés de la principauté normande ${ }^{5}$. Tout au long des deux siècles qui suivent sa

3. Cette étude doit beaucoup aux travaux déterminants de ces trois auteurs, travaux auxquels nous encourageons vivement le lecteur à se reporter (voir la bibliographie finale). Pour une vue d'ensemble sur cet établissement, consulter en premier lieu l'ouvrage collectif L'abbaye bénédictine de Fécamp, ainsi que les contributions du dossier «Fécamp» de la revue Tabularia.

4. Les travaux de G. Nortier, F. Avril et B. Branch peuvent être très ponctuellement complétés grâce aux contributions suivantes: GARAND, 1989, p. 47; COUPRY, 2005, p. 69-70; BAYLÉ, 2005, p. 65-66; TRÂN-DUC, 2006, p. 545-547. Sous l'abbé Guillaume de Rots (1078-1107), la production de manuscrits s'est quelque peu ralentie. Le scriptorium de Fécamp ne paraît pas avoir été actif avant 990: deux manuscrits carolingiens ayant appartenu à La Trinité sont originaires de Fontenelle/Saint-Wandrille; ils proviennent semble-t-il du monastère de Blangy-sur-Ternoise, refuge des moines de Fontenelle dans la seconde moitié du IX ${ }^{\mathrm{e}}$ siècle, puis prieuré de Fécamp à partir de 1032 (LE MAHO, 2004, p. 61-78, en particulier p. 71-78; MÉRIAUX, 2001, p. 404-405). Deux autres manuscrits carolingiens d'origine bretonne en possession de Fécamp (mss Paris, BnF lat. 1535 et lat. 3182 ; cf. LANGEFELD, 1996, p. 21-36 ; ID., 2003, p. 37-39) pourraient avoir la même provenance: plusieurs communautés bretonnes se réfugièrent en effet dans le diocèse de Thérouanne aux IX ${ }^{\mathrm{e}}$ et $\mathrm{X}^{\mathrm{e}}$ siècles. À moins qu'ils n'aient été acquis seulement au XII ${ }^{\mathrm{e}}$-XIII ${ }^{\mathrm{e}}$ siècle par le monastère normand, à l'époque où plusieurs saints bretons (Melaine, Brieuc, Samson, Malo et Jacut) sont entrés dans le mobilier liturgique de l'établissement: des recherches approfondies à leur sujet restent à entreprendre (je remercie à Jean-Luc Deuffic pour ces dernières informations).

5. Véronique Gazeau a récemment rappelé les relations de Fécamp avec d'autres monastères normands, tout en relativisant l'influence de cette abbaye; je tiens au passage à lui exprimer ma gratitude pour 
restauration, des liens étroits existent avec l'abbaye du Mont Saint-Michel, notamment pour la liturgie, la décoration et les échanges de manuscrits ${ }^{6}$. Des relations avec l'Angleterre sont également perceptibles avant et surtout après la conquête de $1066^{7}$. Par la suite, les moines fécampois ont continué à prendre soin de leurs manuscrits: des codices sont encore copiés aux XIII et XIV ${ }^{\text {e }}$ siècles; les volumes sont toujours entretenus au siècle suivant; nombre d'entre eux reçoivent des sommaires et des ex-libris au nom de l'abbaye à cette époque ${ }^{8}$. Et c'est seulement à partir du $\mathrm{XVI}^{\mathrm{e}}$ siècle qu'une dispersion importante des fonds médiévaux paraît s'être amorcée 9 . Ce phénomène, qui n'a fait à ce jour l'objet d'aucune étude systématique, mérite de retenir notre attention : l'objectif du présent article est de dresser un état des lieux en mettant en lumière les principales vagues de démembrement d'une grande bibliothèque monastique normande.

\section{Les plus anciens catalogues}

Le contenu des fonds de l'abbaye peut être partiellement reconstitué grâce, d'une part au nombre important de manuscrits fécampois ayant survécu, d'autre part à plusieurs listes de livres rédigées du XI ${ }^{\mathrm{e}}$ au XVIII ${ }^{\mathrm{e}}$ siècle. Nous avons en particulier la chance de posséder deux anciens catalogues du monastère, qui offrent un témoignage à la fois rare et précieux sur les possessions livresques de l'établissement au cours du Moyen Âge. Ces inventaires ont fait l'objet de plusieurs études minutieuses: Betty Branch, à la suite de Geneviève Nortier et à la faveur des travaux de François Avril, s'est efforcée de retrouver les manuscrits correspondant aux descriptions fournies sommairement dans les deux catalogues médiévaux ${ }^{10}$. Bien que non daté, le premier inventaire a vraisemblablement été exécuté dans le

les conseils qu'elle m'a prodigués dans le forum de la revue Tabularia (GAZEAU, 2002, p. 35-47; voir aussi Herval, 1959, p. 40-42; MUSSET, 1959, p. 64, 67-70 et 78-79; C.H.A.D., t. IV, col. 1130-1131 ; POTTS, 1986, p. 30, 35 ; BATES, 1982, p. 195-196 et 222-226).

6. AVRIL, 1964, p. 504-522, surtout p. 510-514, 520-522 ; ID. 1967, p. 235-238 ; LECLERCQ et BONNES, 1946 ; LE PESANT, 1967, p. 743-750, notamment p. 744-747 ; LECLERCQ, 1967, p. 357-361.

7. GullicK, 2005, p. 83, 85 et 93; WeBber, 2005, p. 95 ; CHAPLAIS, 1959, p. 93-104; ChIBNALL, 1959, p. 127-135. La cathédrale de Salisbury possède un manuscrit réalisé au milieu du XI siècle par le scriptorium de Fécamp (ms Salisbury 89).

8. NorTIER, 1957, p. 12-13 et 18-19; GARAND, 1989, p. 47. Toutefois, l'enrichissement des fonds du $\mathrm{XIII}^{\mathrm{e}} \mathrm{au} \mathrm{XV} \mathrm{X}^{\mathrm{e}}$ siècle est également dû à des dons (notamment plusieurs recueils des œuvres d'Aristote, acquis au $\mathrm{XV}^{\mathrm{e}}$ siècle), ainsi qu'à des achats.

9. NORTIER, 1957, p. 20-25. Comme pour de nombreuses bibliothèques médiévales françaises, la dispersion des manuscrits de cette abbaye au bénéfice de quelques érudits semble surtout imputable aux troubles religieux et politiques de la seconde moitié du XVI et de la première moitié du XVII ${ }^{\mathrm{e}}$ siècle (à ce sujet, voyez AVRIL, 1964, p. 491; VEZIN, 1974, p. 47, 48-54; PALlier, 1988, p. 15).

10. NoRTIER, 1960 , p. 227-237 ; BRANCH, 1979, p. 168-172. La suite de ce paragraphe se base principalement sur LESNE, 1938, p. 584-586; NORTIER, 1957, p. 9-11, 15-17 et 76; BRANCH, 1979, p. 164-168; MUNK OLSEN, 1989, p. 31-36. Voir aussi La bibliothèque imprimée, 2001, p. 3. 
troisième quart du XI ${ }^{e}$ siècle, sous l'abbatiat de Jean de Ravenne ${ }^{11}$. Il donne un aperçu intéressant des œuvres primitivement copiées et acquises à la suite de l'installation des moines bénédictins à Fécamp en 1001. La rédaction du second catalogue doit être placée à la fin du XII siècle, peut-être dans les dernières années de l'abbatiat d'Henri de Sully, peu avant le déclin d'activité du scriptorium ${ }^{12}$. De cent à cent cinquante ans séparent donc ces deux inventaires. Toutefois, ces anciens relevés ne présentent sans doute qu'un état partiel des manuscrits alors en possession de l'abbaye de Fécamp. En effet, au Moyen Âge, les volumes ne sont ni regroupés en un seul endroit, ni conservés dans un fonds unique; dans un souci de mettre au plus près des moines les textes les plus utiles, ils sont dispersés à travers les différents lieux de vie du monastère. Le premier inventaire, qui recense 87 titres parfois réunis sous la même reliure, mentionne principalement des œuvres patristiques et théologiques, ainsi que, dans une moindre mesure, des textes liturgiques ${ }^{13}$. Les 176 volumes du second catalogue, d'une plus grande diversité, correspondent peut-être à un recensement plus complet des manuscrits conservés dans le monastère; des textes scolaires y sont mentionnés ${ }^{14}$. Cependant, l'inventaire était malgré tout loin d'être exhaustif, puisque les textes liturgiques et les glossaires sont cette fois omis. Surtout, chaque volume n'est décrit que par la première œuvre qu'il renferme ${ }^{15}$. Si, dans chacune des deux listes, certaines œuvres sont désignées à la fois par un nom d'auteur et un titre, une seule de ces informations est parfois fournie, ce qui ne facilite guère leur identification: les deux inventaires

11. Ms Rouen, Bibl. mun., 1417 (U. 45), fol. 55v . Ce catalogue a été édité dans BeAurePaire, 1859, p. 158 ; OMONT, 1886, t. I, p. XXIV-XXV et répertorié dans GOTTLIEB, 1890, n² 289; Bibliothèques de manuscrits médiévaux en France, 1987, n 578. Jean de Ravenne, également nommé Jean d’Alie, fut le disciple et le successeur de Guillaume de Volpiano comme second abbé de Fécamp ; selon Lucien Musset, ce fut «un grand abbé, aussi doué pour l'administration que pour les tâches spirituelles» (MUSSET, 1959, p. 79).

12. Ms Paris, BnF, lat. 1928 , fol. $180 r^{\circ}$. Ce catalogue a été édité dans OMONT, 1886, t. I, p. XXV-XXVI (cote erronée) et répertorié dans GoTTLIEB, 1890, n² 290 ; Bibliothèques de manuscrits médiévaux en France, 1987, n 579.

13. Près de la moitié des textes sont des œuvres des Pères de l'Église; un quart sont des bibles, des évangiles et des textes liturgiques; enfin, le dernier quart est constitué d'ouvrages divers, notamment d'histoire, d'hagiographie et de référence.

14. Sept livres scolaires ont fait leur apparition; les arts libéraux étaient absents du catalogue du $\mathrm{XI}^{\mathrm{e}}$ siècle, malgré l'existence dès cette époque de recueils de ce type, tel que le ms Rouen, Bibl. mun., 1470 (O. 32).

15. D'où la présence de certains textes dans le premier catalogue et leur absence dans le second. L'existence d'anciennes tables de contenu pour identifier certains manuscrits se révèle dès lors capitale. Ainsi, le texte des Annales de Flodoard, qui figure aujourd'hui dans le recueil factice Vatican, BAV, Reg. lat. 633, appartenait autrefois à un volume commençant par plusieurs textes hagiographiques, comme le prouve la table du XVe siècle apparaissant sur le dernier feuillet (fol. 80). Dans le catalogue du XII ${ }^{e}$ siècle, le volume est simplement décrit par le premier texte que l'on trouve dans cette table: Vita sancti Columbani ( ${ }^{\circ}$ 142). Cf. GRÉMONT, 1971, p. 25 n 31. Ce manuscrit du début du XI ${ }^{e}$ siècle ne figure pas dans le plus ancien catalogue de l'abbaye, manifestement incomplet. Sur le choix des titres dans les manuscrits et les catalogues médiévaux, voir SHARPE, 2003, p. 34-45 et 69-98. 
ne donnent ainsi qu'un aperçu incomplet et imparfait des textes réellement possédés par l'abbaye au moment où ils ont été rédigés. Pour l'identification des manuscrits, un troisième document vient donc opportunément compléter ces deux catalogues. Il s'agit des Lectiones ad prandium figurant dans un Ordinaire de Fécamp du début du XIII ${ }^{e}$ siècle : renfermant les offices journaliers en usage à l'abbaye, ce texte - précieux car rarement conservé dans d'autres établissements - nous renseigne sur les lectures qui se faisaient au réfectoire, et il donne une liste d'une quarantaine d'œuvres que les moines employaient à cet effet ${ }^{16}$. Dans un tout autre registre, il convient également de signaler l'étude réalisée par dom Gaston Lecroq sur les manuscrits liturgiques de La Trinité de Fécamp, un travail qui a permis de décrire un grand nombre de volumes constituant le mobilier sacré de l'abbaye ${ }^{17}$.

\section{Sous la Commende et pendant les guerres de Religion}

Malgré les vicissitudes rencontrées par La Trinité de Fécamp - incendies, guerres, vols -, il semble que la bibliothèque ait été relativement épargnée au cours du Moyen Âge ${ }^{18}$. Plusieurs inventaires du trésor de l'abbaye, réalisés entre le milieu du XIV e et la fin du XVII ${ }^{\mathrm{e}}$ siècle, montrent que les moines ont su conserver les ouvrages les plus richement reliés, donc les plus convoités et les plus vulnérables, au moins jusqu'au début des guerres de Religion en $1562^{19}$. Toutefois, dès cette

16. Ms Fécamp, Musée de la Bénédictine, 186 (fol. $\left.180 \mathrm{v}^{\circ}-186 \mathrm{r}^{\circ}\right)$. Cf. Bibliothèques de manuscrits médiévaux en France, 1987, n 580 ; LECROQ, 1935, p. 25-31. Ce précieux document a été étudié et édité par D.-B. Grémont, qui s'est efforcé de retrouver les manuscrits correspondants ayant survécu : 25 textes sur 39 ont ainsi pu être retrouvés (GRÉMONT, 1971, p. 1-41, en particulier p. 3 29 et $40-41$ ).

17. LECROQ, 1934, p. 1-64. Cette étude a aussi permis de corriger quelques erreurs des catalogues de la Bibliothèque municipale de Rouen (mss Rouen, Bibl. mun., 223, 243, 291 et 295, p. 12-14, 33 34, 39-43) et du Musée de la Bénédictine de Fécamp (mss Fécamp, Musée de la Bénédictine, 186 et 187, p. 19-23 et 44-46). Toutefois, les travaux de François Avril étant postérieurs, certains manuscrits liturgiques étaient alors inconnus de dom Lecroq : mss Paris, BnF, lat. 258 (Évangéliaire), lat. 3776 (Homéliaire), lat. 5242 (Martyrologe) et lat. 5290, lat. 5296, lat. 5305, lat. 5329, lat. 5362 et lat. 5390 + Vatican, BAV, Reg. lat. 500 et Reg. lat. 633 (légendiers et recueils de vies de saints). Sur les missels de Fécamp, voyez LeroQUAIS, 1924-1934, t. I, p. 194-196, t. II, p. 153 et 377-378, t. III, p.159-160 et 258-259, t. IV, p. 94-96.

18. Nortier, 1957, p. $11,12-13$ et 17; BEAUREPAIRE, 1859, p. 157-158; BRANCH, 1979, p.167; Dubuc, 1959, p. 241-243. Deux incendies frappèrent l'abbatiale en 1168 et en 1460 : des manuscrits liturgiques ont pu périr à ces occasions; une partie du trésor de l'abbaye a été enlevée par Henri II Plantagenêt vers 1152-1154, mais cela ne concernait pas les livres; un vol de manuscrits, dont l'ampleur demeure inconnue, eut lieu en 1284 ; la ville de Fécamp fut exposée à des pillages pendant la guerre de Cent Ans (en 1363 et en 1410) et les moines durent également mettre à l'abri leurs objets les plus précieux à deux reprises (de 1415 à 1419 et en 1422).

19. Les inventaires des années $1362,1375,1400,1425,1499,1502,1505,1550,1560,1617,1649$ et 1682 , édités partiellement par Charles de Beaurepaire, sont conservés aux Archives départementales de la Seine-Maritime (ms Rouen, Arch. dép. de la Seine-Maritime, 7 H 54). Cf. BeaurePAire, 1859 p. 153-170 et 399-411; NORTIER, 1957, p. 13-16 et 20-21; Bibliothèques de manuscrits médiévaux en France, 1987, n 581 ; GOTTLIEB, 1890, nº 291 et n² 292 . Pour une description sommaire du fonds 
époque, l'argenterie et les plus belles reliures d'orfèvrerie ont été vendues pour subvenir aux besoins matériels du monastère, qui connaît alors une importante crise intellectuelle et spirituelle ${ }^{20}$. C'est vraisemblablement dans ce contexte difficile que la conservation des manuscrits a été négligée, au point de laisser parfois des traces irréversibles sur le parchemin: les livres ont été abandonnés ouverts à même le sol dans l'ancien chartrier de l'abbaye, peut-être afin d'échapper aux pillages huguenots des années 1562-1563 ou aux troubles causés par les Ligueurs entre 1591 et $1594^{21}$. C'est sans doute vers la même époque qu'il faut placer les découpages réalisés sur les feuillets de nombreux manuscrits au niveau des peintures frontispices, des lettres ornées et des enluminures ${ }^{22}$. L'inventaire de 1617 , réalisé par dom Charles Martel, révèle que les ouvrages aux reliures les plus précieuses ont déjà disparu à cette époque. Il indique également que divers volumes, qui constituent une autre source de revenus, ont été vendus de la même façon. L'intérêt des érudits de ce temps ${ }^{23}$ pour les textes anciens et le désintérêt des moines pour

des archives de l'abbaye de Fécamp conservé aux Archives départementales $(7 \mathrm{H})$, voyez BLANCHET, 1959 , p. 241-243.

20. NORTIER, 1957, p. 21-22; La bibliothèque imprimée, 2001, p. 4 et 16. Nous sommes à l'époque des abbés commendataires: le concordat de Bologne (1516) permettait désormais au roi de nommer sans élection évêques et abbés de son choix. Sur cette période (de 1519 à 1649 pour Fécamp, même si le cardinal Antoine Bohier fut imposé par Louis XII dès 1505), voyez DUBUC, 1959, p. 182-183; DaOUST, 1959, p. 193-195; ZURfluh, 1959, p. 284-290 ; D.H.G.E. ; HeLlot, 1897, p. 5, 91, 97.

21. NORTIER, 1957, p. 21, 23-24 et n. 84; La bibliothèque imprimée, 2001, p. 2 et 4. De nombreux volumes en gardent les séquelles: jetés précipitamment et sans ordre sur la terre humide, certains ont été attaqués au centre par la pourriture, alors que le début et la fin du recueil sont restés intacts. Ce délabrement de manuscrits est antérieur à l'entrée des livres dans les anciens fonds Bigot et Mareste (première moitié du XVII ${ }^{e}$ s.), puisqu'on retrouve des traces d'humidité dans leurs manuscrits conservés à Rouen et à Paris.

22. AVRIL, 1964, p. 509 n. 1; ID., 1967, p. 236; LECROQ, 1935, p. 13, 15, 16 et 17. Ces mutilations et lacérations de feuillets pourraient-elles être l'œuvre de dom Anselme Le Michel (1601- apr. 1647), moine fameux pour avoir visité une à une les abbayes réformées par la Congrégation de SaintMaur (dont le Mont Saint-Michel, Le Bec, Saint-Evroult, Conches et Jumièges pour la Normandie) et pour avoir réalisé des démembrements de manuscrits? A priori non: d'une part, il n'est pas certain que ce moine ait vécu suffisamment longtemps pour connaître la réforme de Fécamp par la Congrégation à partir de 1650 et qu'il se soit rendu dans cette abbaye; d'autre part, ces opérations semblent avoir été réalisées avant les premières dispersions des fonds mentionnées par dom Charles Martel, donc avant 1617; enfin, dom Le Michel ne s'est pas intéressé aux enluminures (Munk Olsen \& Petitmengin, 1989, p. 419; Gasnault, 1973, p. 209-210; Bruyne, 1925, p. 166-169; NORTIER, 1966, p. 5, 51-52, 113-114, 159; Pellegrin, 1990, p. 358 ; DolbeAU, 1976, p. 150 n. 2 ; ID., 1979, p. 159 n. 3 et la main d'Anselme Le Michel p. 190-191, pl. V). Notons que le roi Henri III (1574-1589) est connu pour s'être constitué une collection d'enluminures à une époque où les abbés commendataires de Fécamp - les cardinaux Charles de Lorraine (1550-1574) et Louis de Guise (1574-1588), appartenant à la famille des ducs de Guise (cf. ZuRfLUH, 1960, p. 286-287) - apparaissent dans l'entourage royal.

23. NORTIER, 1957, p. 22 : en 1576, le jeune prêtre rouennais Vincent Cossard demandait à l'abbé de Fécamp l'autorisation de pénétrer dans son abbaye pour y dresser un catalogue des livres (lettre conservée dans le ms Paris, BnF, fr. 928, fol. 195); on ne sait si cette requête fut exaucée, ni si la réalisation d'un inventaire était le seul objectif visé : l'acquisition de manuscrits rares motivait les philologues et encourageait l'intrusion des érudits dans les bibliothèques monastiques les plus riches. 
leurs livres manuscrits depuis le développement de l'imprimerie ${ }^{24}$ ont également été néfastes à la conservation des fonds monastiques. Grâce à une lettre extrêmement intéressante du bénédictin normand dom Maur Benetot adressée à Luc d'Achery le 27 juin 1655, on sait en particulier que le grand prieur de Fécamp, Campion, a vendu de nombreux manuscrits du monastère ${ }^{25}$; malheureusement, il paraît a priori difficile de préciser s'il s'agit de Nicolas Campion (grand prieur sous la Ligue, à la fin du XVI siècle) ou de Charles Campion (grand prieur au début du XVII e siècle) ${ }^{26}$. Ce fut en tout cas avant le 31 décembre 1649, date du début de la réforme de l'abbaye par les moines de la Congrégation de Saint-Maur.

\section{Les collectionneurs rouennais}

Si l'année de cette vente reste délicate à établir avec précision, il n'en demeure pas moins qu'en Normandie, les acheteurs potentiels appartiennent à une catégorie sociale bien déterminée : à cette époque, c'est principalement la noblesse de robe rouennaise qui s'intéresse à l'acquisition de manuscrits anciens ${ }^{27}$. Jean Bigot (1593-1653), seigneur de Somménil et de Cleuville, conseiller au Parlement de Normandie, fut vraisemblablement le bénéficiaire direct de ces acquisitions. Doyen de la Cour des Aides de Normandie, il avait épousé la fille du premier président du Parlement de Rouen, et il était parvenu à se constituer en 1644 une bibliothèque riche de 6000 volumes contenant plus de 500 manuscrits. Le père Louis Jacob, Léopold Delisle, Henri Omont, Geneviève Nortier et Jean-Dominique Mellot ont successivement attiré l'attention sur cette importante bibliothèque provinciale, considérée comme l'une des plus belles collections privées normandes du

Cossard était d'ailleurs un disciple du philologue de la Manche Guillaume Postel (1510-1581), versé en grec, hébreu et arabe (MAILlaRD, 1985, p. 92).

24. «Les manuscrits anciens ne suscitaient plus guère d'intérêt et furent relégués dans les sous-sols de l'abbaye» (La bibliothèque imprimée, 2001, p. 4). Quelques anciens codices pourraient avoir souffert de mesures prises au début du XVI e siècle par Antoine Bohier : profès, puis abbé de La Trinité (1505-1519) avant de devenir archevêque (1513-1519) puis cardinal de Bourges (1517-1519), il décide de réemployer des «rognures de parchemin» pour en faire de la colle (RENOUX, 1979, p. 116 ; ZuRfluH, 1959, p. 284). Rappelons au passage son choix de donner à son abbaye de SaintOuen de Rouen, plutôt qu'à Fécamp, le De officis que lui avait offert le doyen de Windsor en 1509 (Catalogue des manuscrits en écriture latine portant des indications de date, de lieu ou de copiste, 1985, p. XXI) : peut-être conviendrait-il de réaliser quelques recherches dans la collection réunie par ce prélat?

25. Lettre (Paris, BnF, lat. 17685, fol. 39) publiée à deux reprises par Léopold Delisle et numérisée sur Gallica (DELISLE, 1857, p. 254 n. 1; ID., 1877, p. XXII-XXIV) : «les originaux de quantité, comme martyrologes, obituaires et autres mss. du dit monastère [...] qui ont esté vendus autrefois avec tous les manuscrits de nostre bibliothèque par feu M. Campion, grand prieur ».

26. NORTIER, 1957, p. 22-23 et n. 81-82.

27. Mellot, 1988, p. 455-457, 458 col. b et surtout 462. La lettre de dom Maur Benetot (cf. supra, n. 25) révèle que l'avocat général de la Cour des Aides de Normandie intervenait fréquemment dans les monastères au XVII ${ }^{e}$ siècle : les moines «ayant tous les jours affaire de luy de tous les monastères de cette province à cause de sa charge ». Une telle position créait inévitablement des opportunités pour accéder aux bibliothèques monastiques ou pour acquérir des manuscrits à moindre frais. 
temps ${ }^{28}$. En son sein, les ouvrages provenant de l'abbaye de Fécamp étaient nombreux; ils gardent aujourd'hui encore des traces de leur passage dans les fonds Bigot: les armes gravées avec ex-libris de Jean Bigot apparaissent souvent au verso du premier plat supérieur (contre-plat); des armes gravées similaires figurent encore sur les reliures en cuir de certains volumes. Jean Bigot ayant apparemment acquis personnellement ces manuscrits fécampois lors de la vente opérée par le grand prieur Campion, il faut à notre avis placer ce commerce au début du XVIIe siècle et l'imputer à Charles Campion (1614-1639), plutôt qu'à son prédécesseur Nicolas Campion ${ }^{29}$. Outre Fécamp, Jean Bigot puisa - directement ou non, et visiblement dans une moindre mesure - dans de nombreuses autres bibliothèques monastiques et ecclésiastiques normandes au cours de la première moitié du XVII ${ }^{\mathrm{e}}$ siècle ${ }^{30}$. Léopold Delisle indique également plusieurs sources d'enrichissement des fonds Bigot grâce aux bibliothèques privées d'autres collectionneurs, comme Louis Martel (Rouen), Guillaume du Chemin (Rouen), Jean de la Lande (Caen), Guillaume de La Mare (Caen) et Gabriel du Moulin (Bernay) ${ }^{31}$. Jean Bigot était aussi en contact étroit avec les érudits de son temps - en particulier l'historiographe du roi André Duchesne (1584-1640), mais aussi le père Frédéric Flouet (1584-1662) et le généalogiste Pierre d'Hozier $(† 1660)$ - auxquels il laissait volontiers l'accès de sa bibliothèque.

Le fils de Jean Bigot, le savant Émeric Bigot (1626-1689) ${ }^{32}$, a poursuivi l'accroissement de cet héritage paternel et l'a fait prospérer; ses papiers témoignent en particulier d'un grand intérêt pour les manuscrits grecs. Il visita les grands dépôts littéraires d'Europe et il inspecta les bibliothèques de différents monastères normands, en particulier lors d'un voyage à Évreux, à Conches, à Lyre et au Bec

28. Delisle, 1857, p. 253-254. Sur Jean Bigot, voyez Nortier, 1957, p. 22-23; OmOnt, 1886, p. XXVI; Delisle, 1868, I, p. 322-329; ID., 1877, p. I-VI ; Mellot, 1988, p. 462. Pour un aperçu de son ex-libris et de ses armes, voyez Catalogue général des manuscrits latins: table des t. III à VI, 1981 , p. 479 + planche I ( $\left.\mathrm{n}^{\circ} 3\right)$ et p. 483 + planche XXVI ( $\left.{ }^{\circ} 5\right)$.

29. Sur Charles Campion, voir Dubuc, 1959, p. 182-183 et DaOust, 1959, p. 195-196. Ce dernier auteur remarque que «les désordres s'accrurent sous le priorat de Charles de Campion». Sans doute s'agit-il d'une vente réalisée entre 1614 et 1617, puisque dom Charles Martel paraît y faire allusion dans son inventaire. L'abbaye de La Trinité constitue la principale source d'acquisition de manuscrits pour Jean Bigot: à ce jour, $20 \%$ des manuscrits latins de Bigot (soit 56 mss sur $280 ; 276$ sont conservés à la $\mathrm{BnF}$ et 4 à Rouen) ont été identifiés comme d'origine ou de provenance fécampoise.

30. On trouve dans sa collection des manuscrits provenant des abbayes de Conches, de Saint-Étienne de Caen, du Mont Saint-Michel, de Saint-Wandrille, du Bec, du Valasse, de Valmont, de SaintÉvroult, de Saint-Taurin d'Évreux, des églises de Rouen, d'Évreux, de Bayeux, de Coutances, de Lisieux, de Sées, d'Écouis, des prieurés Notre-Dame de Gournay et Bonne-Nouvelle de Rouen, etc.

31. Louis Martel, ami de Vincent Cossard dont il a été question dans une note précédente; Guillaume de Mara (v. 1470-v.1550), né à Coutances et recteur de l'université de Caen; Gabriel du Moulin (†v.1660), né à Bernay et curé de Menneval.

32. Également appelé Louis-Émery ou Louis-Émeric Bigot. Sur ce personnage, voyez en premier lieu Delisle, 1877, p. VI-XXI ; Mellot, 1988, p. 462. Voir aussi JoASSART, 2006, p. 118 n. 159, 96-97 et 136-139; BALAYe, 1988, p. 213 ; DelisLe, 1871, p. $25 \mathrm{n}^{\circ} 27$. 
effectué en $1665^{33}$. Mais il ne s'est pas procuré de nouveaux manuscrits fécampois en plus de ceux déjà acquis par son père. Sa riche correspondance, en grande partie inédite, témoigne de ses relations érudites avec de nombreux savants, notamment avec Du Cange (1610-1688), Gilles Ménage (1613-1692), Jean-Baptiste Cotelier (1629-1686), Nicolas Heinsius (1620-1681) et Isaac Vossius (1618-1689). Il laissait volontiers l'accès de sa bibliothèque, même en son absence, aux érudits de passage, parmi lesquels nous pouvons citer en 1662 les pères Godefroid Henschen (1601-1681) et Daniel Papebroch (1628-1714), puis, en 1680, le sous-bibliothécaire du Collège de Clermont Jean Hardouin (1646-1729). Il était surtout en contact étroit avec les moines mauristes les plus éminents, tels que Luc d'Achery (1609-1685) et Jean Mabillon (1632-1707). Grande figure de la bibliophilie rouennaise, Émeric Bigot lègue à sa mort une bibliothèque riche de plus de 21000 volumes, dont 522 manuscrits, à son cousin germain Robert Bigot, seigneur de Montville et conseiller au Parlement de Paris ${ }^{34}$. Après le décès de ce dernier en 1692, la collection est achetée par plusieurs libraires parisiens, qui la revendent ensuite au détail durant le mois de juillet 1706, après en avoir établi un catalogue précis pour l'époque ${ }^{35}$. Par chance, les manuscrits ont échappé à la dispersion du reste du fonds Bigot, et notamment des incunables : ils entrent dans la bibliothèque du roi grâce à l'abbé Louvois. De ce fait, la quasi-totalité des manuscrits ayant appartenu à Jean et Émeric Bigot sont aujourd'hui conservés à la Bibliothèque nationale de France, où ils se trouvent principalement dispersés entre les fonds latins, grecs et français ${ }^{36}$.

Antoine de Mareste $(† 1672)$, seigneur d’Alge et avocat général de la Cour des Aides de Normandie, est un second personnage bien connu pour avoir possédé

33. Lettre du 8 août 1665 (Paris, BnF, fr. 17683, fol. 224-225), publiée partiellement par Geneviève Nortier (NorTiER, 1966, p. 138). Les mss Paris, BnF, gr. 3079 à 3117 constituent 39 volumes grecs issus du fonds Bigot. Les mss Paris, BnF, suppl. gr. 1075 et gr. 3091 contiennent des copies des catalogues de Jumièges, de Saint-Ouen de Rouen et de Lyre de la main d'Émeric Bigot (Bibliothèques de manuscrits médiévaux en France, 1987, $\mathrm{n}^{\circ} 870, \mathrm{n}^{\circ} 1671$ et $\mathrm{n}^{\circ} 1034$ ).

34. Il s'agit du fils d'Alexandre Bigot (1607-1675), seigneur de Montville et frère de Jean Bigot.

35. Celui-ci a été imprimé par Léopold Delisle, qui l'a accompagné d'une introduction et de notes savantes: DELISLE, 1877, p. XVII-XIX et 1-105. L'article 50 du catalogue de la collection Bigot est indiqué par erreur comme étant le ms Paris, BnF, lat. 1959 : il s'agit en fait du ms Paris, BnF, lat. 1939. Voir aussi OMONT, 1913, t. 4.2, p. 411-440 (édition de la liste dressée par Nicolas Clément: ms Paris, BnF, Archives de l'ancien régime n. 19, p. 47-75); Bibliothèques de manuscrits médiévaux en France, 1987, n 251 et n² 252 ; NORTIER, 1982, p. 167.

36. On trouve également 13 manuscrits dispersés dans les fonds italien, espagnol, turc, anglais, hébreu et arménien. Quelques-uns sont conservés à la Bibliothèque municipale de Rouen : à l'exception de 4 manuscrits médiévaux fécampois sur lesquels nous reviendrons, il s'agit exclusivement de papiers de Jean Bigot écrits au XVII siècle. Ces derniers ont rejoint ceux des différents membres de la famille Bigot qui se sont succédé à la tête du Parlement de Rouen depuis cette époque : ils forment des recueils acquis par héritage par le marquis de Martainville, fils de Françoise-Louise Bigot. Deux autres manuscrits sont conservés aux Archives départementales de la Seine-Maritime, série E (DelisLe, 1877, p. XX-XXI et appendice III p. XXVI-XXXII; OMONT, 1886, t. I, p. XXX-XXXI et t. II p. IX-XI, 1-69). 
des manuscrits provenant de La Trinité de Fécamp ${ }^{37}$. Certains volumes portent encore l'écu et l'ex-libris daté avec la devise latine de Mareste tracés à la plume; d'autres ont gardé leur reliure de cette époque ${ }^{38}$. Il s'agit donc d'un second acquéreur de manuscrits fécampois lié à la Cour des Aides de Normandie, dont le siège était situé à Rouen. Mais contrairement à ce que suggère Geneviève Nortier, il semble peu probable que les moyens d'acquisition du seigneur d'Alge soient les mêmes que ceux de Jean Bigot et qu'ils doivent être imputés à la vente de Campion: l'existence d'un lien familial permet d'envisager une autre hypothèse à notre avis plus pertinente. Antoine de Mareste avait pour frère le moine de Fécamp dom Jacques de Mareste $(\dagger 1652)^{39}$ : c'est sans doute par l'intermédiaire de celui-ci qu'il est entré en contact avec l'abbaye de La Trinité et qu'il a pu acquérir plusieurs manuscrits de ce monastère. Dans ces volumes, les ex-libris datés se succèdent de 1630 à 1660 ; entre ces deux dates extrêmes, on trouve par exemple des traces d'acquisition en 1640 , en 1645 et en $1650^{40}$. L'avocat général n'a donc pas obtenu simultanément tous les manuscrits de Fécamp entrés en sa possession : il les a acquis pièce par pièce, au cours d'une période s'échelonnant sur au moins une trentaine d'années, et majoritairement autour de 1640.

Jacques et Antoine de Mareste se sont beaucoup intéressés à l'abbaye de Fécamp au point de composer une Histoire de ce monastère: Jacques y travailla jusqu'à sa mort en 1652, et son frère Antoine acheva la rédaction trois ans plus tard, en $1655^{41}$. Le manuscrit autographe de cette œuvre a malheureusement disparu lors de la Révolution, avant que le texte ne soit imprimé. Cet attrait d'Antoine de Mareste pour Fécamp justifie le passage de plusieurs manuscrits, souvent liés à l'histoire de l'abbaye, dans le fonds de sa bibliothèque. Il explique également la présence à Rouen de quatre manuscrits fécampois autrefois possédés par Jean Bigot: Émeric Bigot,

37. Nortier, 1957, p. 22-23, 31 ; OMONT, 1886, p. XXVI-XXVII; LAFFITE, 2005, p. 199. Pour un aperçu de l'ex-libris d'Antoine de Mareste d'Alge photographié à la lumière ultraviolette, voyez Catalogue général des manuscrits latins: table des t. III à VI, 1981, p. $482+$ planche XXI ( $\left.\mathrm{n}^{\circ} 13 \mathrm{c}\right)$. Les mss Rouen, Bibl. mun., 521 (A. 369), 547 (A. 312), 570 (A. 219), 576 (A. 148), 1042 (O. 21), 1049 (O. 33), 1420 (U. 138) et Paris, BnF, nouv. acq. lat. 1137 conservent des ex-libris non grattés et datés, avec la devise latine Anthonius de Mareste, Uni Deo sum athaerens.

38. LAFFITTE, 2005, p. $199 \mathrm{col}$. a : «reliures en peau retournée jaunâtre ornée d'un double filet à froid sur des plats de carton ".

39. Voir la lettre de dom Maur Benetot dont il a déjà été question plus haut (infra, n. 25) : «Monsieur Mareste, advocat général en la cour des aydes, lequel après son [frère], jadis ancien religieux de Fescamp, à présent décédé, s'est employé à l'histoire du dit monastère de Fescamp, qui est maintenant achevée et fera un bien juste volume in-folio ». Cette lettre nous révèle également que Jacques de Mareste n'était guère favorable à la réforme de l'abbaye de Fécamp par la Congrégation de Saint-Maur : "le frère du dit sieur advocat ayant pandant son vivant tesmoigné peu d'affection pour nos Pères et leur establissement dans Fescamp ».

40. Ms Rouen, Bibl. mun., 547 (A. 312) : 1630 ; ms Paris, BnF, nouv. acq. lat. 1137 : 1640 ; ms Rouen, Bibl. mun., 570 (A. 219) : 1645; ms Paris, BnF, lat. 2405: 1650; ms Rouen, Bibl. mun., 576 (A. 148) : 1660 .

41. NORTIER, 1957, p. 31-33; infra, n. 39. 
soucieux d'aider Mareste, n'a pas hésité à lui fournir les matériaux indispensables à son entreprise historique ${ }^{42}$.

En 1672, la collection de manuscrits d'Antoine de Mareste revient par héritage à son fils, qui s'en débarrasse de diverses manières. Il offre environ 58 manuscrits dès le 2 octobre 1677 au ministre des finances Jean-Baptiste Colbert (16191683), par l'intermédiaire du premier président du Parlement de Rouen, Claude Pellot (1613-1683) ${ }^{43}$. Si parmi eux une part importante de volumes provient de l'abbaye cistercienne de Mortemer ${ }^{44}$, cette origine n'est pas exclusive : jusqu'à présent, cinq manuscrits de Fécamp avaient pu être identifiés ${ }^{45}$. Mais ce nombre paraît quelque peu sous-estimé, comme le confirment les récents travaux de Marie-Pierre Laffitte sur les reliures des manuscrits normands possédés par Colbert ${ }^{46}$. En effet,

42. Le témoignage de dom Maur Benetot s'avère une fois de plus décisif: « M. Bigot [...] lui a fourni plusieurs mémoires », et Mareste a ainsi eu accès aux «originaux de quantité [...] qui ont esté vendus autrefois [...] par feu M. Campion, grand prieur» (supra, n. 25). Les quatre manuscrits médiévaux de Bigot aujourd'hui conservés à Rouen - mss Rouen, Bibl. mun., 427 (A. 143), 525 (A. 421), 528 (A. 362) et 1233 (Y. 26) - ont la particularité de provenir de Fécamp et de renfermer des renseignements sur l'histoire de ce lieu (charte de fondation du monastère bénédictin par Richard II en 1001; notes sur la consécration de Saint-Léger en 1223; fondation de Fécamp par Waningne; Chronique de Normandie). Ce dernier volume fait partie des 14 manuscrits que le fils de Mareste a vendus à Fécamp en 1699; prêtés par Émeric Bigot à Antoine de Mareste, ces manuscrits ne furent pas restitués à leur propriétaire. Nous ignorons à ce jour par quel biais trois d'entre eux ont pu entrer à la Bibliothèque municipale de Rouen, mais il est probable qu'ils ont connu le même destin que le quatrième, en étant revendus par le fils de Mareste à quelques établissements religieux (dont Fécamp).

43. Delisle, 1868, t. I, p. 455 et 524-526; Delisle, 1871, p. 26 n $^{\circ} 37 \mathrm{~g}$; NorTIER, 1957, p. 24 ; DolBEAU, 1976, p. 161 n $^{\circ} 25$; OMONT, 1886, p. XXVII; Bibliothèques de manuscrits médiévaux en France, 1987, $\mathrm{n}^{\circ}$ 1046. Une double liste inédite de ces manuscrits, comportant quelques variantes, se trouve dans le ms Paris, BnF, lat. 9363, fol. 208-209v et 210-211 : nous la publierons en seconde partie de cet article (transcription accompagnée de l'identification des volumes conservés).

44. NORTIER, 1957, p. 24 n. 91 ; OMONT, 1886, p. XXVII. Rappelons que Colbert a par ailleurs acquis de nombreux volumes provenant d'établissements normands entre 1677 et 1683 : Mortemer, Savigny, la Noë, Bonport, Échevinage de Rouen et Foucarmont (Dernier état des lieux par MariePierre Laffitte, qui a réactualisé les travaux antérieurs : LAFFITTE, 2005, p. 197-198; DELISLE, 1868, t. I, p. 524-544; ID. 1871 , p. 25 n $^{\circ} 37$ f, p. 26 n$^{\circ} 37$ w et $n^{\circ} 37 \mathrm{z}$; NorTIER, 1982, p. 168). Colbert avait chargé Du Molinet de parcourir la Normandie pour lui procurer des manuscrits; ce dernier visita le Bec et probablement le Mont Saint-Michel en 1678 (NOrTIER, 1966, p. 46, 81).

45. NORTIER, 1966, p. 237. Voir aussi la liste provisoire donnée en fin d'article. Les listes de manuscrits donnés par le fils de Mareste à Colbert en 1677 prouvent que les mss Paris, BnF, lat. 1843 et lat. 5305 formaient alors un volume unique; l'année suivante (1678), deux volumes furent constitués et reliés indépendamment (cf. ms Paris, BnF, Baluze 100, fol. 120 ; DOLBEAU, 1979, p. 200 n. 6 ; fiches de la BnF sur ces deux manuscrits). Le Cartulaire de la pitancerie de l'abbaye de Fécamp (ms Paris, BnF, nouv. acq. lat. 1137), possédé par Mareste, a été enregistré le 8 juin 1922 à la BnF (acquis au libraire M. F. Monier, 4 rue de Clichy à Paris), donc sans passer par Colbert. Merci à Laurence Le Bras (BnF) pour les informations obtenues sur ce manuscrit (Cf. NORTIER, 1960, p. 246).

46. Six manuscrits ont conservé leur reliure exécutée au milieu du XVII siècle pour Antoine de Mareste d'Alge : mss Paris, BnF, lat. 63, lat. 99, lat. 123, lat. 310, lat. 2405 et lat. 2801. Marie-Pierre Laffitte suggère qu'ils sont originaires de l'abbaye de La Trinité de Fécamp, ce qui est déjà attesté pour le ms Paris, BnF, lat. 2405 (LAFFITTE, 2005, p. 199 col. a). Selon nous, les manuscrits suivants, acquis 
le bibliothécaire de Colbert, Étienne Baluze (1630-1718), n'a guère facilité l'identification des manuscrits d'Antoine de Mareste entrés dans la collection de son maitre et aujourd'hui conservés à la Bibliothèque nationale de France : il est le responsable direct et indirect des grattages destinés à masquer les ex-libris de possesseurs antérieurs ${ }^{47}$. Si les autres campagnes de reliure réalisées au cours du XVIII ${ }^{e}$ siècle ont davantage épargné les gardes et les différents éléments des couvertures primitives que ne l'avaient fait les relieurs de Colbert, certaines marques de provenances ont malgré tout pu disparaître à ces occasions. Les mss Paris, BnF, lat. 437 et 708 - deux manuscrits de Fécamp du fonds Colbert n'ayant pas gardé leurs anciennes reliures $^{48}$ - paraissent avoir souffert de tels traitements : selon nous, leur appartenance à Antoine de Mareste peut aujourd'hui être considérée comme une quasi certitude $^{49}$. D'autres manuscrits ont sans doute suivi le même circuit de diffusion et subi des opérations de «maquillage» similaires (grattage d'ex-libris ou/et suppression des pages de garde) de la part de Baluze et de son entourage, voire de relieurs ultérieurs. À notre avis, le contenu de certains volumes est à rapprocher des articles mentionnés dans les catalogues de Fécamp des XI et $\mathrm{XII}^{\mathrm{e}}$ siècles pour lesquels aucune identification satisfaisante n'a pu être proposée à ce jour ${ }^{50}$. D'autre part, en plus de dons à Colbert, le fils d'Antoine de Mareste a également vendu 14 manuscrits, la plupart fécampois, aux religieux de La Trinité en $1699^{51}$. Il a visiblement

par Mareste de 1640 à 1645 (probablement avant les manuscrits de Mortemer), méritent une attention particulière quant à leur possible provenance fécampoise: mss Paris, BnF, lat. 123, lat. 310, lat. 691, lat. 1736, lat. 1916, lat. 1997, lat. 2019 et lat. 2914.

47. LaffitTe, 1988, p. 108, 109 n. 6; BlOCH, 1988, p. 175; LAfFitTe, 2005, p. 198 col. b et p. 199 col. a; DeLISLE, 1871 , p. $24 \mathrm{n}^{\circ} 11$.

48. Leurs couvertures actuelles, aux armes royales de l'Ancien Régime, datent de la fin du XVII ${ }^{\mathrm{e}}$ ou du XVIII $^{e}$ siècle : les feuillets de garde comportant les marques d'anciens possesseurs ont pu être ôtés à l'occasion d'un changement de reliure (au sujet de la campagne d'août 1790, voyez LAFFITTE, 2005, p. 199 col. a). Contrairement aux manuscrits de la BnF provenant du fonds Mareste, ceux provenant du fonds Bigot n'ont pas transité par la bibliothèque de Colbert: ils ont directement intégré la Bibliothèque du roi en 1706. Il est donc surprenant de voir apparaître sans explication le ms Paris, BnF, lat. 437, ayant appartenu à Colbert, dans la liste des manuscrits fécampois provenant de l'ancien fonds Bigot (AVRIL, 1963, appendices; NORTIER, 1966, p. 237).

49. Leur contenu correspond précisément aux descriptions de deux articles présents dans les listes des manuscrits donnés par Mareste à Colbert ( $n^{\circ} 28$ et n 43). Le ms Paris, BnF, lat. 708 (Colbert 6019), de petit format, appartient d'ailleurs à un groupe de manuscrits d'Antoine de Mareste d'Alge intégré en bloc dans le fonds Colbert (cotes 6018 à 6022). Je remercie Marie-Pierre Laffitte pour cette dernière précision, qui révèle l'existence de deux manuscrits (peut-être l'un et l'autre fécampois) de même contenu décrits par une seule entrée dans les deux listes : il s'agit des mss Paris, BnF, lat. 310 et lat. 708 .

50. Mss Paris, BnF, lat. 310 (catalogue de Mareste $n^{\circ} 43$; catalogue du XII ${ }^{\text {e }}$. $n^{\circ} 150$ et 151), lat. 1736 (cat. Mareste $n^{\circ} 10$; cat. XII ${ }^{\mathrm{e}}$ s. $\mathrm{n}^{\circ} 41$ ), lat. 1916 (cat. Mareste $\mathrm{n}^{\circ} 4$; cat. XII ${ }^{\mathrm{e}}$ s. $\mathrm{n}^{\circ} 17$ ) et lat. 2801 (cat. Mareste ${ }^{\circ} 33$; cat. XI ${ }^{\mathrm{e}}$ s. $^{\circ} 35$; cat. XII ${ }^{\mathrm{e}}$ s. $\mathrm{n}^{\circ} 103$ ).

51. NORTIER, 1957, p. 24 ; Bibliothèques de manuscrits médiévaux en France, 1987, n 1047. La liste des 14 manuscrits vendus à Fécamp en 1699 par le fils de Mareste figure dans le ms Montivilliers, Bibl. mun., 5 et dans les dossiers de Montfaucon (ms Paris, BnF, lat. 13074, fol. 210). Deux d'entre eux (mss Rouen, Bibl. mun., 243 et 284) n'étaient pas fécampois avant cette date (NorTIER, 1957, p. 9 n. 18 ; LECROQ, 1935, p. 33-34). 
opéré de la même manière avec un ou plusieurs manuscrits acquis par le prieuré Bonne-Nouvelle de Rouen au début du XVIII ${ }^{\text {siècle }}{ }^{52}$. Nous pouvons légitimement penser que d'autres établissements ont pu bénéficier d'un tel commerce, même si l'héritier ne s'est sans doute pas séparé de l'ensemble des manuscrits avant sa mort ${ }^{53}$.

En rappelant la présence de manuscrits fécampois dans les collections Bigot et Mareste, nous avons décrit les phénomènes de dispersion sur lesquels nous sommes le mieux documenté. Nous allons à présent étudier les phases de démembrement les moins connues et les plus obscures des fonds de la bibliothèque de Fécamp en tentant de les clarifier.

Un troisième personnage de la noblesse de robe rouennaise mérite d'être mentionné comme possesseur de manuscrits de La Trinité : il s'agit de Claude Sarrau $(\dagger 1651)$, conseiller au Parlement de Rouen, puis au Parlement de Paris à partir de 1639. Toutefois, nous ne connaissons à ce jour qu'un seul volume fécampois - un recueil de vies de saints - lui ayant appartenu ${ }^{54}$. Il est fort probable que Claude Sarrau l'a acquis grâce à ses relations avec Jean Bigot (1593-1653) et Antoine de Mareste $(\dagger 1672)$, ses confrères rouennais : il semble en effet peu vraisemblable qu'il ait bénéficié personnellement des ventes de Campion, et cette acquisition reste visiblement un acte isolé. Soulignons toutefois la possibilité d'une obtention de ce codex par l'intermédiaire des collectionneurs orléanais Paul et Alexandre Petau, qui ont donné plusieurs livres à Sarrau ${ }^{55}$ et qui possédaient eux-mêmes quelques volumes provenant de Fécamp. Claude Sarrau était le correspondant à Paris de la reine Christine de Suède (1626-1689), qui l'avait chargé de lui procurer des manuscrits ${ }^{56}$. Or ce volume fut offert en 1648 par les soins de Sarrau à Isaac Vossius, l'un des érudits des Pays-Bas avec qui il entretenait une correspondance régulière. À cette époque, vers 1649, Christine de Suède avait engagé Vossius pour l'administration de sa bibliothèque et c'est ainsi que le manuscrit passa dans la collection de cette reine, puis à la Bibliothèque Apostolique Vaticane, suivant un parcours qui va à présent retenir notre attention plus en détail.

52. Le ms Rouen, Bibl. mun., 576 (A. 148) provenant de Fécamp est entré en possession du prieuré rouennais au début du XVIII ${ }^{\mathrm{e}}$ siècle comme l'indique l'ex-libris daté de 1720 . Le cas du ms Rouen, Bibl. mun., 1420 (U. 138) serait intéressant à étudier, car il pourrait être similaire (toutefois, son origine fécampoise n'est pas établie à ce jour).

53. Il se pourrait qu'une partie des manuscrits fécampois aujourd'hui conservés à Rouen et à Fécamp sans figurer dans l'inventaire de dom Feray puisse provenir du fonds Mareste. Une étude approfondie de ce groupe de manuscrits reste à réaliser (voir la liste finale).

54. Ms Vatican, BAV, Reg. lat. 500 (AVRIL, 1965, p. 217-221). Sur Sarrau, voyez B.U.A.M. ; BOUQUET, 1891, p. 95-154. Au moins deux autres manuscrits sont connus pour avoir appartenu à ce collectionneur.

55. MeYIER, 1947, p. 129, 130, 140 et surtout 213 n. 73; RONZY, 1924, p. 293.

56. Il essaya sans succès d'acquérir la bibliothèque des Mesmes pour cette reine. 


\section{Les collectionneurs orléanais}

En plus du précédent, nous connaissons à ce jour quatre volumes ou/et fragments de manuscrits fécampois conservés au Vatican. Il s'agit de tout ou partie des mss Vatican, BAV, Reg. lat. 107, Reg. lat. 633, Reg. lat. 755 et Ottob. lat. 909 ${ }^{57}$; comme les trois premiers, ce dernier appartenait autrefois à la reine Christine de Suède : il fait partie d'un lot de 240 volumes passé en 1690 dans le fonds Ottoboni ${ }^{58}$. Trois de ces manuscrits fécampois ont la particularité de n'être que des fragments (membra disiecta) insérés dans des recueils factices constitués entre la fin du XVI ${ }^{e}$ et le début du XVII siècle. Mais tous ont surtout comme point commun leur ancienne appartenance au fonds Petau. Cette importante bibliothèque, étudiée partiellement par le néerlandais Karel Adriaan De Meyier, a été constituée dès 1590 par le collectionneur orléanais Paul Petau (1568-1614), puis a été enrichie par son fils Alexandre $(\dagger 1672)^{59}$. Les manuscrits qui la composent ont ensuite suivi un parcours tumultueux que les nombreux travaux sur la dispersion de la bibliothèque de Fleury ont rendu célèbre ${ }^{60}$ : sans entrer dans les détails, retenons simplement qu'Isaac Vossius, l'un des bibliothécaires de la reine Christine de Suède ${ }^{61}$, acquiert pour celle-ci en 1650 la majeure partie de la bibliothèque d'Alexandre Petau ${ }^{62}$, non

57. LAUER, 1898, 491-523 ; AVRIL, 1964, p. 504-514, 522-525 ; ID., 1965, p. 209-216; Pellegrin, 1978, p. 542 ; MOSTERT, 1989, p. 276. Le ms Vatican, BAV, Reg. lat. 107 est entièrement fécampois; les autres sont des recueils factices et seuls les fragments suivants sont fécampois : mss Vatican, BAV, Reg. lat. 633, fol. 39-80, Reg. lat. 755, fol. 100-105 et Ottob. lat. 909, fol. 1-49 (la fin de ce dernier manuscrit correspond au ms Paris, BnF, lat. 5062, de l'ancien fonds Bigot).

58. AVRIL, 1965, p. 209; Pellegrin, 1978, p. 23 n. 2 et p. 26.

59. Paul et Alexandre Petau furent conseillers au Parlement de Paris (B.U.A.M. ; MEYIER, 1947, p. 1-2 et p. 128-129 et 217-219; Aubert, 1909, p. 249 n. 2; Delisle, 1868, t. I, p. 287-289; Boutemy, 1950, p. 168-169; PEYRAFORT-HUIN, 2001, p. 176-177). Il existe plusieurs catalogues (plus ou moins complets) des manuscrits d'Alexandre Petau : voyez Bibliothèques de manuscrits médiévaux en France, 1987, n $1464-1475$.

60. Le lecteur intéressé par la dispersion des fonds Petau peut consulter les ouvrages suivants (liste non exhaustive) : PELLEGRIN, 1978, p. 23-26; ID., 1942, p. $78-79$ (réimpr. 1990, p. 310-311) ; ID., 1959, p. 5-8 (réimpr. 1990, p. 159-162); ID., 1984-1985, p. 155-157 (réimpr, 1990, p. 285-287); ID., 1985, p. 274 (réimpr., 1990, p. 284) ; MEYIER, 1947, p. 60-61, 130-139 et 217-219; BOUTEMY, 1950, p. 169-170 ; VIDIER, 1965, p. 30-33 et 215; MOSTERT, 1989, p. 29-31; OUY, 1989, p. 88 ; PEYraforT-HuIN, 2001, p. 565-569; Lumières de l'an mil en Orléanais, 2004, p. 196; DeLIVRÉ, 2006, p. 494-495; AUVERT, 1909, p. 249-250 et p. 271-272, 1911, p. 302-305; DelisLe, 1868, p. 287-289; DeLISLE, 1871, p. $24 \mathrm{n}^{\circ} 18$ et 22.

61. Christine de Suède avait chargé ses deux bibliothécaires, Isaac Vossius et Nicolas Heinsius de parcourir l'Europe pour lui procurer des manuscrits. On retrouve des volumes du fonds Petau dans les collections de chacun d'eux. Sur la dispersion de la collection Heinsius, voir http://elec.enc.sorbonne.fr/cataloguevente/notice186.php. Sur Vossius, voir B.B.K.L., t. XIII, 1998, p. 100-104.

62. Alexandre Petau ne vend pas tous ses manuscrits en 1650 (22 manuscrits sont acquis pour la bibliothèque du roi par Nicolas Clément en 1669). Après sa mort, ce qui subsiste de sa bibliothèque (le catalogue de 1672 indique encore 300 vol.) est vendu en plusieurs occasions par ses héritiers, notamment en 1698, 1707 et 1720. Ami Lullin de Genève achète un grand nombre de manuscrits à cette dernière date, qu'il lègue plus tard à sa ville. On retrouve aujourd'hui des manuscrits provenant de l'ancien fonds Petau au Vatican, à Genève, à Leyde, à Leipzig, à Paris, à Londres, à Copenhague, à Gand ou encore à Stockholm. 
sans enrichir sa propre collection au passage ${ }^{63}$. Après diverses péripéties, les manuscrits de la reine entrent finalement à la Bibliothèque Apostolique Vaticane, où ils se trouvent aujourd'hui répartis dans les fonds Reginenses et Ottoboni. Il reste donc à déterminer de quelle manière le fonds Petau a pu posséder plusieurs fragments de manuscrits fécampois aujourd'hui conservés à Rome suivant le trajet que nous venons de décrire.

L'hypothèse la plus séduisante consiste à voir en Pierre Daniel d'Orléans (v. 1530-v. 1604) ${ }^{64}$, juriste et bailli de l'abbaye de Fleury, le possesseur des manuscrits de Fécamp entrés dans le fonds Petau. L'existence du ms Vatican, BAV, Reg. lat. 755 favorise en effet cette idée: il s'agit d'un recueil factice probablement constitué par Pierre Daniel à partir d'un manuscrit carolingien sénonais et d'un fragment de manuscrit fécampois du milieu du XI ${ }^{e}$ siècle ${ }^{65}$. D'une part, on sait que Pierre Daniel a prêté des manuscrits à son concitoyen et ami Paul Petau ${ }^{66}$; d'autre part, à la mort de Daniel, Petau et son cousin germain Jacques Bongars (1554$1612)^{67}$ furent les acquéreurs de la bibliothèque du défunt ${ }^{68}: c^{\prime}$ est ainsi que ce manuscrit est entré en possession de Paul Petau. Le fait de retrouver aujourd'hui à Berne un autre manuscrit de Fécamp ayant appartenu à Pierre Daniel renforce sérieusement cette hypothèse, déjà suggérée il y a quelques années par François Avril ${ }^{69}$. Il s'agit du ms Berne, Burgerbibliothek, 162 acquis par Jacques Bongars à la mort de Daniel ${ }^{70}$. D'après l'ex-libris apparaissant sur le premier feuillet, Pierre Daniel l'aurait acquis en 1564: il a donc, d'une manière ou d'une autre, profité des troubles rencontrés par l'abbaye de Fécamp au début des guerres de Religion pour se procurer un certain nombre de manuscrits. En plus de manuscrits fécampois,

63. Bien que Vossius résidât en Angleterre depuis 1670, ses manuscrits furent vendus à l'Université de Leyde par ses héritiers (v. 1690).

64. B.U.A.M. ; MEYIER, 1947, p. 58-60 ; MOSTERT, 1989, p. 29-30 ; RONZY, 1924, p. 237 ; HAGEN, 1873, p. 4-11 et 21-35. Son père, François Daniel, était l'ami de Jean Calvin (1509-1564) et d'Odet de Coligny, sur lequel nous reviendrons.

65. AVRIL, 1964, p. 522-525; MOSTERT, 1989, p. 276.

66. Berger, 1885, p. 717-718; MOSTERT, 1989, p. 30 : le ms Berne, Burgerbibliothek, 450 conserve le reçu d'un opuscule prêté par Pierre Daniel à Paul Petau, écrit et signé de la main de ce dernier.

67. B.U.A.M. ; MEYIER, 1947, p. 12-14, 60-61 ; STEIGER (von), 1960, p. $86-99$ et 1983 ; VIDIER, 1965, p. 31. Jacques Bongars, érudit et diplomate, était seigneur de la Boudry et de la Chesnay, près d'Orléans.

68. MeYier, 1947, p. 60-61 ; PELlegrin, 1959, p. 5 (réimpr. 1990, p. 159); OuY, 1989, p. 88 ; PALlier, 1988 , p. 15 ; MOSTERT, 1989 , p. 31.

69. AVRIL, 1964, p. 505, 514-515 et 523 ; AVRIL, 1965, p. 210. En plus du ms Berne, Burgerbibliothek, 162, l'auteur suggère la possession par Daniel des mss Vatican, BAV, Reg. lat. 107, Reg. lat. 755 et Ottob. lat. 909 acquis ensuite par Paul Petau; cela a depuis été démontré pour le second (MOSTERT, 1989, p. 276).

70. AVril, 1964, p. 514-522; Mostert, 1989, p. 60 ; MeYIER, 1947, p. 68 . Sur le passage des 500 manuscrits et 3000 volumes imprimés de Jacques Bongars à la Bibliothèque de Berne en 1628/1632 via René et Jacques Graviseth (1598-1658), voyez, B.U.A.M.; MEYIER, 1947, p. 61 ; OUY, 1989, p. 88, t. II, p. 15 ; PELlEGRIN, 1942, p. 69 (réimpr. 1990, p. 301) ; STEIGER (von), 1960, p. 86-92 et 1983 ; VIDIER, 1965, p. 32 ; TISCHLER, 2001, p. 1030-1033; MOSTERT, 1989, p. 31. 
d'autres codices normands ont pu entrer dans sa collection à cette époque : nombreuses furent en effet les abbayes de cette région pillées par les armées protestantes entre 1562 et $1563^{71}$. Et s'il faut en croire Gerda Huisman, parmi les nombreux volumes français possédés par le collectionneur orléanais, plusieurs livres provenaient de Normandie ${ }^{72}$. À ce propos, une judicieuse mise en garde formulée par Élisabeth Pellegrin à ses lecteurs mérite d'être rappelée ici: une tendance fréquente consiste à attribuer systématiquement et sans preuve à la bibliothèque de Fleury tous les manuscrits annotés par Pierre Daniel; cette démarche abusive est la source de nombreuses erreurs, puisque le bailli de Fleury est très loin d'avoir exclusivement acquis des manuscrits de Saint-Benoît-sur-Loire. Sa bibliothèque, aujourd'hui dispersée aux quatre coins de l'Europe, renfermait nombre de manuscrits provenant de Saint-Victor de Paris, Saint-Mesmin de Micy, Ferrières-en-Gâtinais ou encore Saint-Florentin de Bonneval: sa main apparait dans plusieurs manuscrits de ces abbayes. Des volumes de plusieurs maisons cisterciennes, dont Vauluisant et Châalis, se retrouvent également dans sa collection et plusieurs manuscrits sénonais, parfois conservés sous forme de fragments dans des recueils factices, lui ont appartenu ${ }^{73}$. Fécamp vient donc s'ajouter à la liste, déjà longue et sans doute loin d'être complète, des établissements religieux d'où proviennent les livres de Pierre Daniel.

Certains indices codicologiques viennent conforter cette hypothèse. Nous avons vu que les manuscrits de Fécamp du fonds Petau ont la particularité d'être en majorité des fragments introduits dans des recueils factices constitués entre la fin du XVI ${ }^{\mathrm{e}}$ et le début du XVII ${ }^{\mathrm{e}}$ siècle. Or Pierre Daniel est célèbre pour avoir démembré de nombreux manuscrits ${ }^{74}$, en particulier afin d'en procurer les portions jugées intéressantes à son ami Pierre Pithou $(1539-1596)^{75}$. Il est également connu

71. Ce fut notamment le cas pour Saint-Ouen de Rouen, Saint-Pierre-sur-Dives, Jumièges, SaintWandrille, Saint-Étienne de Caen, Savigny et Le Bec (NorTIER, 1966, p. 5, 50, 158, 178 et 188; LAFFITTE, 2005, p. 198 col. a ; C.H.A.D. t. I col 1366-1367, t. VI col. 1254-1256, t. XIII col 144, 496-496 et 608-611 ; D.H.G.E. ; La bibliothèque imprimée, 2001, p. 2 et 4 ; PEYRAFORT-HuIn, 2001, p. 167 n. 3). Nous verrons que des manuscrits de ces différentes abbayes, dont certains (et peut-être tous?) ont appartenu à Pierre Daniel, sont aujourd'hui conservés au Vatican, à Leyde et à Berne.

72. Huisman, 1984, p. 125 et n. 12: l'auteur se fonde sur les travaux de H. Hagen et de K. A. de Meyier pour faire cette affirmation.

73. Voir notamment: MEYIER, 1947, p. 59, 63-64, 84-88, 91-116, 213-215; OUY, 1989, p. 86-89, en particulier p. 88 col. b; PELLEgRIN, 1942, p. 71-77 (réimpr. 1990 , p. 304-309); ID., 1959, p. 7 et 51-53 (réimpr. 1990, p. 161 et 205-207); ID., 1963, p. 20 (réimpr. 1990, p. 246) ; ID., 19841985, p. 157 (réimpr. 1990, p. 287) ; MOSTERT, 1989, p. 41 ; BOURGAIN, 1999, p. XXXI ; DELIVRÉ, 2006, p. 481-503, principalement 494-495; STIRNEMANN, 2006, p. 174 et 179-180. Pierre Daniel a acquis des manuscrits classiques ailleurs qu’à Fleury, et notamment dans la région Troyes-SensAuxerre. Parmi les autres provenances de manuscrits comportant des marques de possession de Pierre Daniel, il convient de citer Saint-Denis de Paris, Saint-Martin de Limoges et peut-être Cluny.

74. Humphreys, 1989, p. 128; Munk Olsen \& Petitmengin, 1989, p. 419; Pellegrin, 1959, p. 5-9 (réimpr. 1990, p. 159-163); ID., 1979, p. 83 (réimpr. 1990, p. 257); ID., 1984-1985, p. 156 (réimpr. 1990, p. 286) ; ID. 1985, p. 274 (réimpr. 1990, p. 284); MOSTERT, 1989, p. 30 et 37.

75. Les érudits ayant bénéficié de la libéralité de Pierre Daniel, qui prêtait volontiers ses manuscrits, furent nombreux (voyez RoNZY, 1924, p. 237-238; HAGEN, 1873, p. 16). 
pour avoir confectionné des recueils regroupant des fragments de diverses origines ${ }^{76}$. La Bibliothèque nationale de France conserve un grand nombre de ces recueils hétérogènes, donnés et prêtés par Daniel à Pithou ${ }^{77}$ et où l'on peut observer des notes de leurs mains respectives ${ }^{78}$. Quelques-uns de ces volumes factices sont entrés dans les bibliothèques privées d'autres collectionneurs, suivant des cheminements plus ou moins complexes ${ }^{79}$ : des membra disiecta de codices fécampois pourraient donc figurer dans des recueils hétérogènes ayant appartenu aux collections de ces individus, sans que l'origine des fragments en question n'ait pu être identifiée comme telle à ce jour. Nous savons également qu'après avoir acquis les manuscrits de Pierre Daniel, Paul Petau a lui-même rassemblé des fragments provenant de cette bibliothèque, ainsi que de sa propre collection ${ }^{80}$, pour constituer de nouveaux recueils factices souvent reliés avec du parchemin souple ${ }^{81}$. Ces caractéristiques

76. Pierre Daniel est le responsable de la confection d'un grand nombre de recueils factices (cf. MosTERT, 1989, p. 205, 257, 274, 277, 279, 280 et aussi p. 62, 67, 105, 213, 222, 272, etc.).

77. Grâce à Françoise Bibolet, la dispersion de la bibliothèque de Pierre Pithou via son frère François (1543-1621) et son ami Jacques-Auguste de Thou (1553-1617) vient de faire l'objet d'une étude remarquable, désormais incontournable (BIBOLET, 1998, p. 497-521) voir aussi: CORON, 1988, p. 106; LAFFITTE, 1988, p. 108-109; BLOCH, 1988, p. 160, 161, 177 n. 59; BALAYE, 1988, p. 209, 222 ; DeLISLE, 1871, p. 26 n³7q; BourgaIn, 1999, p. XXVII; Bibliothèques de manuscrits médiévaux en France, 1987, n 1545-1546; Pellegrin, 1959, p. 54 (réimpr. 1990, p. 208). L'essentiel de la collection Pithou est aujourd'hui conservé à Paris, Troyes, Montpellier et Lanvellec (collection Rosanbo). Le reste est dispersé à travers le monde (Colmar, Metz, Baltimore, Berlin, Berne, Boston, Bruxelles, Copenhague, Florence, Göteborg, La Haye, Leipzig, Leyde, Londres, New York, Philadelphie, Saint-Pétersbourg, Vatican).

78. Bibolet, 1998, p. 503 ; Pellegrin, 1959, p. 5 n. 3 et p. 6 n. 4 et n. 5 (réimpr. 1990, p. 159-160); ID., 1979, p. 84-85 (réimpr. 1990, p. 258-259); ID., 1984-1985, p. 157 (réimpr. 1990, p. 287). Voyez les mains de Pierre Daniel et Pierre Pithou dans le Catalogue général des manuscrits latins: table des $t$. III à VI, 1981, p. 479 + planche IV ( $\left.\mathrm{n}^{\circ} 2\right)$ et p. 480 + planche VII $\left(\mathrm{n}^{\circ} 10\right)$.

79. Des recueils factices constitués par Pierre Daniel sont passés entre les mains de Pierre Pithou, de Claude Fauchet (1530-1602), de Jacques-Auguste de Thou (1553-1617), de Paul et Alexandre Petau, de Jacques Bongars et d'Isaac Vossius (voir le diagramme 1). Le ms Leyde, Bibl. univ., Voss. lat. O 60 offre l'exemple d'un recueil factice annoté à la fois par Pierre Daniel, Pierre Pithou, Claude Fauchet, Paul et Alexandre Petau et Isaac Vossius (MeYIER, 1947, p. 64-65; VIDIER, 1965, p. 33 n. 41 ; PELLEGRIN, 1959, p. 6 n. 4 et p. 24, réimpr. 1990, p. 160 et 178; ID., 1979, p. 84-85, réimpr. 1990, p. 258-259; MOSTERT, 1989, p. 30 ; BOURGAIN, 1999, p. XVI).

80. Paul Petau a acquis de nombreux manuscrits n'ayant a priori pas transité par Pierre Daniel (la main de celui-ci n'apparaissant pas dans ces volumes). Ils provenaient notamment d'Angers (Saint-Aubin, Saint-Serge et Saint-Maurice), Saint-Thierry de Reims, Saint-Germain d'Auxerre, Saint-Bénigne de Dijon, Saint-Symphorien de Metz, La Chaise-Dieu, l'Ile-Barbe, Royaumont, La Sorbonne, Périgueux, Saint-Pierre de Rebais, Saint-Martin de Séés, etc. et peut-être aussi de Corbie (Vezin, 1974, p. 31, 50-54 ; LafFitTe, 1979, p. 84-85 ; Dolbeau, 1979, p. 159; Meyier, 1947, p. 81-127; GANZ, 1990, p. 171-173).

81. Paul Petau est également connu pour les titres, les notices et les notes qu'il a ajoutés en marge supérieure de ses manuscrits, ainsi que pour ses signatures, ses cotes, ses devises latine (Cum nova tot quaerant, non nisi prisca peto) et grecque. Son fils Alexandre a quant à lui, en plus de notes et d'ex-libris (devise: Non est mortale quod opto), inscrit de nombreuses tables de contenu caractéristiques (MEYIER, 1947, p. 24-31, 146-150 et 217-219; Lire le manuscrit médiéval, 2005, p. 261 et 265 ; Boutemy, 1950, p. 169). Pour un aperçu des mains de Paul et Alexandre Petau, voyez MeYier, 1947, planche entre les p. 28-29; PEYrafort-Huin, 2001, p. 176-177, fig. 1 et 2. 
codicologiques ne correspondent guère à la description des volumes des anciens fonds Bigot et Mareste: s'ils ont renfermé quelques manuscrits incomplets, ils n'ont guère possédé de recueils factices comportant des fragments de provenances diverses. Jean Bigot et Antoine de Mareste attachèrent même un soin tout particulier à leurs manuscrits : ils les ont entretenus et ils les ont fait relier, ce qui témoigne de leur amour des livres; le dépeçage de codices n'était assurément pas une pratique courante chez ces deux collectionneurs rouennais, qui agissaient plus en bibliophile qu'en philologue, contrairement à un Pierre Daniel ou un Paul Petau par exemple. Les pratiques codicologiques des deux collectionneurs orléanais différent donc très nettement de celles de leurs homologues normands. Nous tenons là une sérieuse piste pour voir en Pierre Daniel le possesseur initial des manuscrits de Fécamp et des recueils factices aujourd'hui conservés au Vatican et à Berne dont il a été question plus haut ${ }^{82}$; l'ancien bailli de Fleury pourrait aussi avoir bénéficié de la dispersion des fonds d'autres bibliothèques monastiques normandes, comme plusieurs auteurs n'ont pas manqué de le suggérer avant nous ${ }^{83}$.

À ce propos, l'étude des manuscrits de la Vita Karoli d'Eginhard, réalisée récemment par Matthias Tischler s'avère extrêmement intéressante. Parmi les 134 exemplaires de cette œuvre examinés en détail par le chercheur de Heidelberg, environ une quinzaine de volumes sont d'origine ou de provenance normande ; ils appartiennent au groupe «Normandie - Südengland» qui transmet une tradition particulière du texte d'Eginhard ${ }^{84}$. Or plusieurs de ces codices ont appartenu à des philologues des XVI ${ }^{\mathrm{e}}$-XVII ${ }^{\mathrm{e}}$ siècles, dont Pierre Daniel, Claude Fauchet ${ }^{85}$, Paul et Alexandre Petau, Jacques Bongars et Isaac Vossius ${ }^{86}$. Nous les retrouvons aujourd'hui

82. Notons que le responsable de la confection de certains de ces recueils factices pourrait aussi bien être Pierre Daniel que Paul Petau.

83. En particulier Hermann Hagen, François Avril et Gerda Huisman. Si cette hypothèse s'avère exacte, nul doute que d'autres manuscrits et fragments (provenant de La Trinité de Fécamp, mais aussi d'autres établissements religieux normands) soient aujourd'hui conservés à Paris, au Vatican, à Berne et à Leyde, voire à Genève, à Troyes, à Montpellier, à Stockholm, à Oxford, etc. Des manuscrits de Pierre Daniel sont également conservés à Londres et à Amsterdam; d'autres, de Claude Fauchet, le sont à Londres, à Berlin, à Aix et à Dijon. De nombreuses bibliothèques d'Europe pourraient donc être concernées.

84. TISCHLER, 2001, p. 20-44, 103-104, 897-1104 et stemmata p. 1101 et 1312-1313; Léopold Delisle avait déjà attiré l'attention sur la parenté de plusieurs de ces manuscrits du fait de leurs contenus communs: DeLISLE, 1910, p. 506-522, en particulier p. 518-521.

85. Conseiller au Châtelet de Paris et Président de la Cour des monnaies, Claude Fauchet entretenait des relations érudites avec son ami Pierre Pithou, mais probablement aussi avec Pierre Daniel et Jacques-Auguste de Thou. Sa riche bibliothèque parisienne lui fut dérobée pendant la Ligue (en 1588-1589). Il s'en constitua une autre par la suite. Des manuscrits de Fauchet ont été acquis par Paul Petau (MeYIER, 1947, p. 70-73; SIMONNET, 1863, p. 425-470, en particulier p. 436).

86. TISCHLER, 2001, p. $20 \mathrm{n}^{\circ} 4$, p. $28 \mathrm{n}^{\circ} 39$ et $\mathrm{n}^{\circ} 40$, p. $32-33 \mathrm{n}^{\circ} 68,71,72,80,81$ et 87 , p. $38 \mathrm{n}^{\circ} 100$ et 101, p. 40 n $^{\circ} 112$, p. 1022-1033; MOSTERT, 1989, p. 64 et 198; BOURGAIN, 1999, p. XXX. Pierre Daniel a possédé deux manuscrits de Saint-Pierre-sur-Dives (mss Berne, Burgerbibliothek, 208 et Paris, BnF, lat. 152) et sans doute le recueil factice provenant partiellement de Fécamp (ms Vatican, BAV, Ottob. lat. 909). Claude Fauchet a lui-même eu ces trois manuscrits entre les mains (prêt de 
principalement dans les bibliothèques de Paris, du Vatican, de Leyde et de Berne ${ }^{87}$. Les travaux de Tischler confirment que Pierre Daniel a bien possédé des manuscrits normands et notamment deux exemplaires de la Vita Karoli provenant de SaintPierre-sur-Dives. Les manuscrits étudiés par Elisabeth Van Houts pour ses travaux sur l'Histoire de Guillaume de Jumièges - remaniée et continuée par Orderic Vital et Robert de Torigni - révèlent une dispersion analogue de plusieurs manuscrits normands ${ }^{88}$. De même, la description de deux manuscrits de Dudon de Saint-Quentin réalisée par Gerda Huisman nous permet d'aboutir aux mêmes conclusions. Un premier exemplaire, vraisemblablement d'origine normande, est passé par Pierre Daniel et Jacques Bongars avant d'entrer à la bibliothèque de la Bourgeoisie de Berne. Un second exemplaire, probablement de même origine, est aujourd'hui conservé à Leyde après avoir appartenu à Isaac Vossius ${ }^{89}$. Enfin, l'un des rares exemplaires de l'Histoire ecclésiastique d'Orderic Vital, présent à Berne, a appartenu à Jacques Bongars ${ }^{90}$. En poursuivant les investigations, nous pourrions sans doute multiplier les exemples de ce genre ${ }^{91}$. Rappelons que déjà, au XIX ${ }^{\mathrm{e}}$ siècle, Léopold Delisle avait souligné la présence de manuscrits normands à la Bibliothèque Vaticane ${ }^{92}$. Certains d'entre eux sont d'ailleurs assurément passés par l'ancien fonds Petau. Pierre Daniel, Claude Fauchet, Paul et Alexandre Petau, Jacques Bongars et Isaac Vossius : six personnages que nous avons déjà rencontrés au cours de notre étude, et qui ont pu jouer un rôle plus ou moins direct dans la dispersion des codices de Fécamp et de divers autres établissements normands ${ }^{93}$.

Pierre Daniel, avec ou sans l'intermédiaire de leur ami commun Pierre Pithou, qui a peut-être possédé le second?). Après la mort de Daniel, le premier de ces manuscrits a appartenu à Jacques Bongars; Paul et Alexandre Petau ont possédé le troisième, ainsi que deux autres codices provenant de Rouen (?) et du Bec (mss Leyde, Bibl. univ., Voss. lat. F 77 et BPL 20). Ces deux derniers manuscrits, aujourd'hui conservés à Leyde, ont appartenu à Isaac Vossius.

87. Mss Paris, BnF, lat. 152 (Saint-Pierre-sur-Dives), lat. 4877 (Savigny), lat. 4937 (Nord de la France ou Normandie), lat. 5997 (Saint-Pierre-de-Préaux), lat. 5999 (Rouen) et lat. 14663 (Rouen). Ms Vatican, BAV, Ottob. lat. 909 (Fécamp). Mss Leyde, Bibl. univ., BPL 20 (Le Bec) et Voss. Lat F 77 (Rouen?). Ms Berne, Burgerbibliothek, 208 (Saint-Pierre-sur-Dives). Deux autres manuscrits sont conservés à Rouen : mss Rouen, Bibl. mun., 1158 (Rouen) et 1173 (Jumièges).

88. VAN HOUTS, 1992, p. 77. Une partie de ces manuscrits, apparentés à l'exemplaire de Robert de Torigni (renfermant la Vita Karoli d'Eginhard), correspond aux exemplaires normands décrits par Matthias Tischler. Voir cependant Tischler, 2001, p. 1100 n. 656.

89. Ms Berne, Burgerbibliothek, 390 et ms Leyde, Bibl. univ., Voss. Lat. Fol. 47 (HUISMAN, 1984, p. 123-125).

90. Ms Berne, Burgerbibliothek, 355. Cf. STEIGER (von).

91. Il serait par exemple intéressant d'étudier les manuscrits de l'Histoire des Lombards de Paul Diacre (près de 200 exemplaires connus, dont environ la moitié pour les $\mathrm{XI}^{\mathrm{e}}$ et XII $\mathrm{X}^{\mathrm{e}}$ siècles), en particulier ceux réunis par Waitz (1878) dans une série D regroupant des exemplaires d'origine normande et anglaise. Cf. AVRIL, 1965, p. 212-213; BOUGARD, 1994, p. 11.

92. DELISLE, 1876, p. 474, 490-494, 494-500, 519-527: ces manuscrits proviennent en particulier du Bec, de Saint-Wandrille et de Saint-Étienne de Caen. Voir aussi NorTIER, 1966, p. 71 n. 57, 82, 83, 169 n. 18,176 et 182 .

93. Hormis ceux de Fécamp, Geneviève Nortier (NORTIER, 1966, p. 59-60, p. 115 n. 118, 155, 158159, 171, 188, 239-240) et François Avril (AVRIL, 1964, p. 492-504 ; ID., 1965, p. 222-226, 227-237 
Il reste à déterminer de quelle manière Pierre Daniel a pu se procurer les manuscrits normands, en particulier fécampois, entrés en sa possession. Comme pour un grand nombre de collectionneurs de cette époque, la formation de la bibliothèque constituée par le philologue orléanais reste très mystérieuse. Les ex-libris apposés par ses soins sur un grand nombre de volumes entrés dans sa collection montrent que les acquisitions ont été réalisées au cours d'une dizaine d'années, de 1560 à $1569^{94}$. Toutefois, la majeure partie de l'accroissement a été réalisée en seulement deux ans, de 1564 à 1565, c'est-à-dire dans les années qui suivent immédiatement les premiers pillages huguenots. Cela confirme que Pierre Daniel a su profiter des premiers désordres dus aux guerres de Religion pour enrichir sa collection personnelle. Sans doute a-t-il obtenu ses manuscrits auprès d'intermédiaires, voire de rabatteurs, dont on ne connaîtra probablement jamais le nom. Ces derniers étaient toutefois suffisamment renseignés pour «écrémer » les bibliothèques monastiques en prélevant uniquement quelques volumes jugés intéressants à cette époque - c'est-à-dire principalement ceux renfermant des œuvres classiques et historiques - tout en laissant volontairement de côté les livres de culte et les ouvrages liturgiques, patristiques, théologiques, hagiographiques, etc. Ces individus sont à l'origine de la naissance, puis du développement, d'un véritable marché du manuscrit dans la seconde moitié du XVI ${ }^{e}$ siècle, comme en témoigne la diversité des établissements monastiques qui ont alimenté les collections privées de ce temps ${ }^{95}$. De par la variété et la quantité des œuvres amassées par Pierre Daniel en seulement quelques années, on peut supposer qu'il connaissait parfaitement les filières et les rouages de ce nouveau marché : le collectionneur orléanais était manifestement en relation étroite avec des fournisseurs de premier ordre, dont les identités restent à ce jour énigmatiques ${ }^{96}$. Nous aimerions cependant attirer l'attention des chercheurs sur le rôle probable de la famille de Coligny

et 246-247) indiquent plusieurs manuscrits normands aujourd'hui conservés au Vatican (7 manuscrits, dont 5 ayant appartenu à l'ancien fonds Petau, 1 au Couvent Saint-François d'Assise et 1 au Collège de Clermont), à Leyde (1 manuscrit ayant probablement appartenu à l'ancien fonds Vossius) et à Berne (1 manuscrit ayant appartenu à l'ancien fonds Bongars) : 3 proviennent de Saint-Ouen de Rouen, 2 du Bec, 2 du Mont Saint-Michel, 1 de Jumièges et 1 de Saint-Pierre de Préaux (la plupart de ces établissements ont été pillés par les Huguenots en 1562 ou en 1563).

94. MeYier, 1947, p. 58 et 68-69.

95. Le profil des collectionneurs de la seconde moitié du XVI ${ }^{\mathrm{e}}$ et du début du XVII ${ }^{\mathrm{e}}$ siècle permet de suggérer l'existence d'un réseau philologique à la fois amical et familial dans la mouvance du Parlement de Paris. La plupart des collectionneurs sont en effet des juristes et des avocats de ce parlement, tel les Dupuy (Clément, Claude, Pierre et Jacques), les Pithou (Pierre et François), les Petau (Paul et Alexandre), les de Thou (Christophe et Jacques-Auguste), les Daniel (Pierre et François), Antoine Loisel, Philippe Hurault de Cheverny, Papire Masson, etc. D'autres gravitent autour de ces lieux ou sont en relation avec ces individus, comme Claude Fauchet, Jacques Bongars, Nicolas Le Fèvre, etc. Remarquons que parmi eux, nombreux sont ceux ayant appartenu au cercle des élèves du jurisconsulte Jacques Cujas (1522-1590).

96. On voit mal un seul homme parcourir tout un pays (région ligérienne, Paris et Île-de-France, Oise, Normandie, Picardie, Champagne, nord de la Bourgogne, etc.) encore en proie à des troubles violents à la recherche de bonnes occasions. 
à ce niveau. En effet, une proximité avec les protestants opérant à partir d'Orléans en 1562-1563 et surtout avec le cardinal Odet de Coligny (1517-1571), pourraient expliquer l'acquisition par Pierre Daniel de manuscrits dérobés à des abbayes en Orléanais, Sénonais, Auxerrois, Champagne, nord de la Bourgogne, Picardie, Normandie et Pays chartrain de 1560 à 1569. Ami du calviniste François Daniel, Odet de Coligny avait choisi le fils de ce dernier, Pierre, comme bailli de Fleury. Malgré l'officialisation de son adhésion au protestantisme en 1561, le cardinal, qui cumulait les prébendes, pu conserver ses fonctions d'abbé commendataire dans les nombreux prieurés et monastères dont il avait le bénéfice, comme par exemple à Vauluisant et à Saint-Benoît-sur-Loire. Il était donc à la tête d'au moins deux établissements dans lesquels Pierre Daniel s'est procuré plusieurs livres avant même les troubles et les pillages de $1562^{97}$. Et la dernière année d'acquisition de manuscrits par Pierre Daniel (1569) coïncide remarquablement avec l'époque où Odet de Coligny se voit contraint de fuir la France et de trouver refuge en Angleterre. De plus, tout au long des guerres de Religion, le cardinal a pu acquérir nombre de manuscrits par l'intermédiaire de ses frères : l'Amiral de France Gaspard de Coligny (1519-1572) et le Colonel général de l'infanterie François d'Andelot (1521-1569) étaient alors les principaux chefs protestants actifs du prince de Condé Louis de Bourbon (1530-1569) ${ }^{98}$; ils sont intervenus militairement dans les régions précédemment citées en prenant pour cible de nombreux établissements religieux. La Normandie ne fut guère épargnée par ces troubles: outre l'abbaye de Fécamp, de nombreux autres monastères de cette région furent victimes des déprédations perpétrées au cours des luttes opposant ces protestants révoltés aux catholiques radicaux dirigés par les Guise ${ }^{99}$. Ces quelques éléments nous invitent à penser qu'Odet de Coligny et ses frères étaient extrêmement bien placés pour fournir des manuscrits à Pierre Daniel : sans doute constituent-ils la principale source d'approvisionnement du collectionneur tout au long de ces dix années. Quant à la passion philologique du bailli de Fleury, constatons qu'elle apparaît précisément en 1560, année où il suit à Bourges les cours du jurisconsulte Jacques Cujas (1522-1590) ${ }^{100}$. Grand philologue, Cujas avait inculqué à ses élèves

97. Odet de Coligny est connu pour avoir fourni des manuscrits à Pierre Daniel : cf. RONZY, 1924, p. 238 n. 1 ; Pellegrin, 1959, p. 8 (réimpr. 162).

98. L'amiral de Châtillon, Gaspard de Coligny, était le chef militaire des protestants et le gouverneur d'Île-de-France et de Picardie. Il est intervenu à plusieurs reprises en Normandie de 1560 à 1563 où il était secondé par le comte Gabriel de Montgomery (1526-1574). On compte plusieurs collectionneurs de manuscrits au sein de la famille de Coligny (B.B.K.L., t. I, 1990, p. 1094-1096; D.H.G.E. ; NorTIER, 1966, p. 178-179; De MeYIER, 1947, p. 96-97; MOlinier, 1885, p. 76 n. 209 et p. 254 n. 592). Sur le rôle probable des soldats de Condé dans le pillage des bibliothèques monastiques, voyez LAFFITTE, 1989, p. 108.

99. En particulier Saint-Ouen de Rouen, Le Bec, Jumièges, Saint-Wandrille, Saint-Étienne de Caen, Saint-Pierre-sur-Dives, Savigny, etc. La famille des Guise comporte plusieurs cardinaux, abbés commendataires de nombreuses abbayes (notamment en Normandie).

100. Pellegrin, 1959, p. 6 et 10 (réimpr. 1990, p. 160 et 164); Mostert, 1989, p. 30, en particulier note 16 ; BIBOLET, 1998, p. 497, 498499 et 503. 
son amour des livres et des textes classiques ${ }^{101}$ : ce n'est guère un hasard si les inventaires de sa bibliothèque nous sont parvenus grâce à deux de ses anciens élèves $^{102}$ et si plusieurs d'entre eux devinrent à sa suite de grands philologues et de grands bibliophiles. C'est d'ailleurs à Bourges que Pierre Daniel fit la connaissance de Pierre Pithou, qui est alors son condisciple aux cours de Jacques Cujas: les deux hommes se lièrent d'une solide amitié et se découvrirent des passions érudites communes.

\section{Les abbés commendataires de Fécamp}

Un autre circuit de dispersion des manuscrits fécampois mérite d'être mentionné. Un bel exemplaire de Dudon de Saint Quentin, originaire du Mont SaintMichel mais entré très tôt en possession des moines de Fécamp, est aujourd'hui conservé à Berlin dans le fonds Phillipps ${ }^{103}$. Cette bibliothèque conserve également un recueil factice renfermant le texte complet du Libellus de revelatione, edificatione et auctoritate Fiscannensis monasterii ${ }^{104}$. Ces deux manuscrits provenant de Fécamp ont appartenu au Collège de Clermont à Paris, où le jésuite Jacques Sirmond (15591651) les a consultés dans la première moitié du XVII siècle. Ils ont ensuite suivi un trajet bien connu jusqu'à Berlin, après être passés dans les collections Mermann et Phillipps ${ }^{105}$. Comment expliquer le passage de manuscrits fécampois au Collège

101. Pierre Daniel, Jacques-Auguste de Thou, Claude Dupuy, Pierre et François Pithou et Jacques Bongars furent quelques-uns des très nombreux élèves du jurisconsulte Jacques Cujas; tous furent de grands philologues; les trois derniers sont parvenus à acquérir de beaux débris de la bibliothèque de leur maître, malgré les dispositions testamentaires recommandant la dispersion de celle-ci (B.U.A.M. ; CORON, 1988, p. 102; MOSTERT, 1989, p. 30).

102. Jean de Limoges nous a transmis une liste de 182 manuscrits réalisée vers 1574 (ms Paris, BnF, lat. 4552, fol. 288-294), tandis que François Pithou a produit au début du XVII siècle une copie de l'inventaire testamentaire de 1590 recensant 371 manuscrits (ms Lanvellec, collection Rosanbo 228 [276], fol. 38-72). Ces deux listes, publiées par Henri Omont, nous renseignent sur l'accroissement et les échanges opérés par Cujas pendant une quinzaine d'années. Le fait de trouver un exemplaire de l'Histoire des Normands de Guillaume de Jumièges dans l'inventaire de 1590 $\left(n^{\circ} 167\right)$, œuvre qui n'apparaissait pas encore dans le catalogue de 1574, laisse présager d'un accroissement en partie au détriment de monastères normands entre ces deux dates ; cela vient confirmer les soupçons formulés par Geneviève Nortier concernant son acquisition probable de manuscrits du Mont Saint-Michel (OMONT, 1885, p. 233-237; OMONT, 1888, p. 632-641 ; NORTIER, 1966, p. 79; Bibliothèques de manuscrits médiévaux en France, 1987, n 505-506).

103. Ms Berlin Deutsche, Staatsbibliothek, Phillipps 1854; voyez AvRIL, 1964, p. 521 n. 3; ID., 1967, p. 236; HUISMAN, 1984, p. 123 ; ARNOUX, 1991, p. 138.

104. Ms Berlin Deutsche, Staatsbibliothek, Phillipps 1696, fol. 150-159 (ARNOUX, 1991, p. 138).

105. À la suite à l'expulsion des Jésuites du Collège de Clermont - devenu Collège Louis-le-Grand en 1682 -, la bibliothèque de cet établissement est acquise en grande partie par le savant hollandais Gérard Meermann (1722-1771) lors d'une vente tenue le 5 juillet 1763. Son fils Jean Meermann (1753-1815) hérite de la bibliothèque paternelle, l'enrichi et la lègue à sa mort à la ville de La Haye. Mais la collection est bientôt revendue et sir Thomas Phillipps se porte acquéreur de 650 manuscrits $\left(n^{\circ} 1388-2010,3078-3087\right.$ et 6756-6782) entre le 8 juin et le 3 juillet 1824 . Enfin, la colossale bibliothèque privée de ce dernier est dispersée en diverses occasions à partir de 1886 par ses héritiers. La Bibliothèque royale de Berlin achète dès 1887 la plupart des manuscrits du Collège de Clermont 
de Clermont dès la première moitié du XVII siècle, alors que cet établissement n'avait été fondé que dans la seconde moitié du siècle précédent? En 1603, le cardinal François de Joyeuse (1562-1615) ${ }^{106}$, d'une famille d'anciens ligueurs, devient abbé commendataire de Fécamp (1603-1615). Successivement archevêque de Narbonne (1581-1584) et de Toulouse (1584-1590), il est nommé « Protecteur des affaires de France en cour de Rome» en 1589. Au début du XVII ${ }^{\mathrm{e}}$ siècle, il obtient finalement le siège archiépiscopal de Rouen (1604-1615), ainsi que le bénéfice de cinq nouvelles abbayes, dont Fécamp et le Mont Saint-Michel pour la Normandie. Il joue dès lors un rôle important dans cette région, où il fonde pour la Compagnie de Jésus un séminaire à Rouen et un collège à Dieppe. Les postes clefs occupés tout au long de sa carrière ecclésiastique lui ont permis de se constituer une riche bibliothèque, léguée à sa mort aux Jésuites du Collège de Clermont : nos deux manuscrits fécampois, et probablement divers autres manuscrits normands, faisaient alors partie de sa collection. Ce circuit de diffusion explique sans doute aujourd'hui la présence d'un certain nombre de manuscrits français dans le fonds Phillipps de la bibliothèque de la ville de Berlin ${ }^{107}$. François de Joyeuse n'est d'ailleurs pas le seul abbé commendataire à avoir puisé dans les fonds de la bibliothèque de Fécamp, ou à avoir permis à son entourage de le faire : ainsi, Louis Odespung de la Meschinière, vicaire général à l'archevêché de Reims, a sans doute pu se procurer grâce à l'archevêque Henri de Lorraine, abbé commendataire de Fécamp (1616-1641), un autre exemplaire du Libellus de revelatione, edificatione et auctoritate Fiscannensis monasterii, hélas aujourd'hui perdu ${ }^{108}$.

ayant transité par Meermann et Phillipps (MYNBY, 1954, p. 19, 25-38; ID., 1960, p. 22-50; ARNOUX, 1991, p. 138; NORTIER, 1966, p. 113, 123, 137, 142; VIDIER, 1965, p. 37 ; AVRIL, 1964 p. 493 ; VeZIN, 1974, p. 62-63; Bourgain, 1999, p. XXV; MECH, 1988, p. 59 col. b, 60 col. a et 63 col. a ; OMONT, 1909, p. I-XI ; PEYRAFORT-HUIN, 2001, p. 233-234 et 500-505).

106. ZurfluH, 1960, p. 288-289; B.B.K.L., t. III, 1992, p. 777-778; B.U.A.M.; D.H.G.E. : "Comme la plupart des évêques grands seigneurs de l'Ancien Régime, le cardinal de Joyeuse cumula les bénéfices bien rentés » en étant abbé commendataire de plusieurs établissements. Il succède à ses frères Anne d'Arques (1561-1587), Antoine-Scipion (1565-1592) et Henri du Bouchage (1563-1608) comme quatrième duc de Joyeuse; «mignons » du roi Henri III, le premier de ses frères avait été Gouverneur de Normandie (1583-1587) et le troisième fut Gouverneur d'Anjou, du Maine, de Touraine et du Perche (1583-1587), puis duc de Joyeuse (1592/3-1599), Gouverneur Général du Languedoc, Gouverneur de Narbonne et Maréchal de France (1596 à 1599), avant de se retirer du siècle comme moine capucin sous le nom d'Ange en 1599. Dernier survivant masculin, François de Joyeuse hérita des bibliothèques de ses frères.

107. Cela explique également la présence de volumes normands à Paris, puisqu'un lot important de manuscrits du fonds Phillipps a pu être obtenu par la Bibliothèque nationale de France en 1908 (NORTIER, 1982, p. 171 ; OMONT, 1909, p. I-XI). La dispersion des manuscrits de l'abbaye cistercienne de Pontigny permet d'avoir un aperçu de la multiplicité des lieux de conservation de l'ancienne collection Phillipps (PEYRAFORT-HuIn, 2001, p. 234, tableau 2). Un ms de Saint-Évroult et trois de Lyre sont indiqués par Geneviève Nortier dans l'ancien fonds de sir Thomas Phillipps: ont-ils suivi un circuit de dispersion analogue, en passant par la collection du cardinal de Joyeuse, par le Collège de Clermont puis par le fonds Meermann?

108. ARNOUX, 1991, p. 140. Sur l'archevêque de Reims Henri de Lorraine : ZURFLUH, 1960, p. 289-290. 


\section{Autres chemins de dispersion}

Pour les XVIe et XVIIe siècles, un dernier circuit de dispersion de bibliothèques monastiques normandes mérite d'être brièvement signalé, bien qu'il ne paraît pas avoir affecté l'abbaye bénédictine de Fécamp: durant la Ligue, JacquesAuguste de Thou fut «chargé de parcourir la Normandie et la Picardie pour s'assurer du loyalisme des gouverneurs et des villes... C'est alors qu'il pénétra dans la bibliothèque à l'abandon de l'abbaye de Corbie. Une visite certainement prolongée puisqu'il mit de côté pour son propre compte plusieurs livres» ${ }^{109}$ : se contenta-t-il de visiter Corbie? En fit-il de même dans les autres monastères normands et picards? On sait par exemple que son ami Nicolas Le Fèvre (15441612) s'est personnellement rendu au Mont Saint-Michel où il inspecta la bibliothèque en $1582^{110}$. Toutefois, ces deux individus ne paraissent pas avoir visité la bibliothèque bénédictine de Fécamp, et à ce jour aucun d'eux n'est d'ailleurs connu pour avoir possédé de manuscrits de cet établissement.

Avant de passer aux dispersions postérieures au milieu du XVII siècle, il nous reste à aborder le cas de deux manuscrits de Fécamp aujourd'hui conservés dans le fonds latin de la Bibliothèque nationale de France, et qui ne sont pas sans poser quelques difficultés puisque, contrairement aux autres, ils ne proviennent ni de Bigot, ni de Mareste: en premier lieu, nous avons le ms Paris, BnF, lat. 564, décrit dès le XVII ${ }^{e}$ siècle dans les inventaires de Nicolas Rigault $\left(n^{\circ} 2050\right)$ et des frères Dupuy ( $\mathrm{n}^{\circ}$ 2267). Ce manuscrit est donc entré dans la collection royale au plus tard à l'époque où Nicolas Rigault officie comme garde de cette bibliothèque ${ }^{111}$. Les travaux récents de Marie-Pierre Laffitte permettent de mieux connaitre l'histoire de ce codex, qui fait partie des 400 manuscrits de la famille Hurault acquis par les soins de Nicolas Rigault pour la Bibliothèque du roi en 1622. Les membres de cette famille, originaire du Val de Loire et au service de la branche capétienne régnante, ont amassé un grand nombre de manuscrits au cours du XVI siècle. L'un d'eux, Philippe Hurault (1527-1599), comte de Cheverny et conseiller au Parlement de Paris (1562), également connu comme mécène ${ }^{112}$, est à l'origine du regroupement de ces volumes de provenances diverses et variées. Proche du roi de France Henri II (1547-1559) et de ses fils, les rois Charles IX (1560-1574) et surtout

109. CORON, 1988, p. 102. Son cousin par alliance, Claude Dupuy, possédait des manuscrits de Corbie. 110. NorTier, 1966, p. 79. La bibliothèque de Nicolas Le Fèvre passa à son ami Jacques-Auguste de Thou par testament en 1612 (LAFFITTE, 1988, p. 108-109). Le Fèvre était en contact avec Jacques Cujas, dont nous avons parlé plus haut, et avec plusieurs membres du cercle philologique gravitant autour du Parlement de Paris.

111. Nicolas Rigault (1577-1654) est garde de la Bibliothèque du roi de 1615 à 1645 ; les fils de Claude Dupuy, Pierre (1582-1651) et Jacques Dupuy (1591-1656), lui succèdent à partir de cette date (CORON, 1988, p. 124 n. 19). Rappelons que les manuscrits de Bigot et de Mareste n'entrèrent à la BnF respectivement qu'en 1706 et en 1732 (via Colbert dans ce dernier cas).

112. Dorat, Ronsard, Baudouin, Delbène, de Sainte-Marthe ou encore Papire Masson appartiennent au cercle de lettrés ayant bénéficié de la protection de Philippe Hurault (RONZY, 1924, p. 105-107 et 135). 
Henri III (1574-1589), il fut notamment sous ce dernier lieutenant général de l'Orléanais et du Pays chartrain (1582), puis chancelier de France (1583-1599). À sa mort, sa collection passe à son fils cadet homonyme, évêque de Chartres (15791620), avant d'être vendue le 8 mars 1622 à la Bibliothèque du roi ${ }^{113}$. La présence du ms Paris, BnF, lat. 564 dans la collection Hurault laisse entrevoir la possibilité d'une acquisition au cours de la première vague de dispersion des manuscrits de Fécamp : les fournisseurs de Philippe Hurault sont les mêmes que ceux de Pierre Daniel d'Orléans; là encore, Odet de Coligny constitue un pourvoyeur potentiel tout désigné ${ }^{114}$. En second lieu, le cas du ms Paris, BnF, lat. 2771 provenant du fonds de La Mare reste à éclaircir : la présence sur le premier feuillet d'un ex-libris du $\mathrm{XIV}^{\mathrm{e}}$ siècle a permis aux rédacteurs du catalogue de la Bibliothèque nationale de suggérer une provenance de La Trinité de Fécamp, bien que cette abbaye ne soit pas explicitement nommée ${ }^{115}$; se pourrait-il que ce manuscrit du XII ${ }^{\mathrm{e}}$ siècle vienne en réalité d'un autre établissement dédié à la Sainte-Trinité? La note inscrite en addenda dans les tables de ce catalogue publiées en 1981 confirme qu'il s'agirait plutôt de la Chartreuse de La Trinité de Champmol, à Dijon ${ }^{116}$. Betty Branch, qui n'a pu connaître cette note au moment de ses travaux, a indiqué sans réserve ce codex comme provenant de Fécamp ${ }^{117}$. Nous préférons pour notre part rejeter cette attribution peu convaincante : les ex-libris de La Sainte-Trinité de Fécamp ne sont pas de ce type puisque le terme domus n'est jamais utilisé et que Fiscannensi(s) ou Fescamp est systématiquement précisé ; de plus, la présence de réclames à la fin de chaque cahier ne caractérise pas les manuscrits de Fécamp du XII ${ }^{\text {e }}$ siècle. D'ailleurs, dans le cas d'une provenance fécampoise effective, nous ne pourrions nous expliquer par quel biais Philibert de La Mare $(\dagger 1687)$, conseiller du Parlement de Bourgogne à Dijon, aurait pu se le procurer ${ }^{118}$.

113. LAFFiTTE, à paraître: ms Paris, BnF, lat. 564 ([Hurault C 62-66], Rigault I 2050, Dupuy I 2267, Regius 4367). Philippe Hurault était le beau-frère de Jacques-Auguste de Thou. Je tiens à remercier Marie-Pierre Laffitte de m'avoir communiqué son article avant publication. Sur les ramifications de cette famille de collectionneurs, voir aussi MEYIER, 1947, p. 185-186.

114. Odet de Coligny a fourni plusieurs manuscrits au roi Charles IX (cf. mss Paris, BnF, lat. 2312, 5724 et 7730 dans l'inventaire de Marco Mostert; Lumières de l'an mil en Orléanais, 2004, p. 196; VIDIER, 1965, p. 32 n. 33; Pellegrin, 1959, p. 8 n. 1, réimpr.; ID., 1990, p. 162 n. 1) : il a donc aussi pu en fournir à un proche de ce roi, Philippe Hurault. À moins que ce dernier se soit personnellement servi dans la bibliothèque royale, comme certains volumes de sa collection reliés aux armes de Henri II le laissent penser (LAFFITTE, à paraittre). Notons également que Pierre Daniel, avocat au Parlement de Paris comme Philippe Hurault, fréquentait plusieurs individus du cercle de lettrés gravitant autour de celui-ci (supra, n. 112) : Papire Masson, Dorat, Alphonse Delbène, etc.

115. Catalogue général des manuscrits latins de la Bibliothèque nationale, t. III, 1952, p. 68: «Auf. 1, exlibris du XIVe s. : "Iste liber est domus Sancte Trinitatis", sans doute La Sainte-Trinité de Fécamp".

116. Catalogue général des manuscrits latins de la Bibliothèque nationale: table des t. III à VI, 1981, p. 11. Le ms. Dijon Bibl. mun. 117, provenant de cette abbaye, présente un ex-libris comparable.

117. BRANCH, 1979, p. 171: «Julianus Pomerius, De vita contemplativa, BN 2771 ».

118. Il était au contraire bien placé pour acquérir un manuscrit provenant de la Chartreuse de La Trinité de Champmol, située dans sa région. Sur sa bibliothèque entrée dans la bibliothèque du roi en 1719, voir DeLISLE, 1868, t. I, p. 361-364. 


\section{De la période mauriste à la Révolution}

Avec l'entrée des moines mauristes et de leur réforme dans les murs de l'abbaye de Fécamp en $1650^{119}$, la dispersion des volumes de la bibliothèque monastique parait s'être fortement ralentie. Le travail intellectuel est alors remis en vigueur et les moines bénédictins sont sollicités pour diverses entreprises d'édition, tant religieuses que profanes. Fécamp compte, avec dom Guillaume Fillastre (16341706) et dom Jean-Philippe Le Cerf de la Viéville (1677-1748), deux écrivains reconnus de la littérature monastique érudite, historique et critique ${ }^{120}$. Le monastère accueille également de nombreux autres moines versés en théologie, philosophie, droit, politique, arts, sciences, médecine, histoire, géographie, etc. comme en témoignent les nombreuses acquisitions de livres imprimés traitant de ces disciplines ${ }^{121}$. Vers 1680 , deux inventaires, l'un pour les livres manuscrits, l'autre pour les livres imprimés, sont réalisés ${ }^{122}$. Deux pouillés sont également dressés pour énumérer les bénéfices dépendant du monastère, et deux plans de l'abbaye sont établis pour le Monasticon Gallicanum dirigé par dom Michel Germain (1645-1694): ces documents, ainsi qu'une copie du catalogue des livres manuscrits, sont expédiés dans la seconde moitié du XVIIe siècle au siège de la Congrégation, à SaintGermain-des-Prés ${ }^{123}$. Une brève histoire des abbés de Fécamp, peut-être utile à la nouvelle édition des Gallia christiana de dom Denis de Sainte-Marthe (16501725) ${ }^{124}$, et divers matériaux utiles aux éditions des œuvres de saint Augustin ${ }^{125}$ suivent le même chemin. Il est probable que les moines ont également communiqué certains de leurs manuscrits à Saint-Ouen de Rouen, devenu centre d'études

119. Ce paragraphe s'appuie sur les travaux suivants: DAOUST, 1959, p. 193-201, 203-218 et 229-252; GAILlarD, 1959, p. 219-228; MONTIER, 1960, p. 17-44; ROUET, 2005, p. 22-23; La bibliothèque imprimée, 2001, p. 2, 4-5, 10, 12-13 et 15; MUNK OLSEN, 1989, p. 39.

120. Dom Toutain est un troisième écrivain fécampois reconnu.

121. En 1691, le prieur de Fécamp Benoît Buquet consacre 6000 livres, somme considérable pour l'époque, à l'achat de livres imprimés.

122. Ces deux catalogues n'ont malheureusement pas été retrouvés. Nous connaissons leur existence grâce aux ex-libris et aux dates d'entrée dans les catalogues apposés dans les ouvrages imprimés, généralement sur la page de titre ( Ex libris monasterii sanctissime Trinitatis Fiscannensis calalogo inscriptus»), ainsi que grâce à la copie du catalogue des manuscrits réalisée par dom Feray avant 1699 (voir plus loin).

123. Mss Paris, BnF, lat. 11814, fol. 209 et 210-211, lat. 11820 ( $\mathrm{n}^{\circ} 40$ et $\mathrm{n}^{\circ} 57$ ) et lat. 13069, fol. 25-43. Cf. NORTIER, 1960, p. 247 ; ID., 1982, p. 169-170.

124. Il s'agit du mss Paris, BnF, lat. 12778, fol. 101-104 (XV e siècle). Les mss Paris, BnF, lat. 12777 à 12780 sont des recueils factices constitués de documents classés provenant de diverses abbayes de France; ils ont été recueillis au XVII siècle, notamment par dom Le Michel (voir plus haut son rôle en Normandie), Mabillon (1632-1707), Chantelou (1617-1664), etc. Cf. DAOUsT, 1959, p. 234 ; NORTIER, 1960, p. 246; ID., 1982, p. 169-170.

125. Ms Paris, BnF, lat. 11645, fol. 227-228 («Tria operum sancti Augustini manuscripta diversae magnitudinis volumina reperiuntur in bibliotheca Fiscanensis monasterii, quorum subsequitur index universus») et fol. 351-352v. Je dois ces informations à Monique Peyrafort et à l'Institut de Recherche et d'Histoire des Textes. 
bénédictines de la Normandie suite à sa réforme par la Congrégation de SaintMaur en $1660^{126}$. Au siècle suivant, en 1737, une nouvelle bibliothèque est installée au-dessus du réfectoire et du dortoir, à l'étage de l'aile nord du cloître: longue de 122 pieds et éclairée par 12 fenêtres, elle permet de regrouper en un même lieu une grande partie des ouvrages autrefois disséminés à travers l'ensemble du monastère. Quelques années plus tard, en 1764, dom Lenoir (1721-1792) ${ }^{127}$ copie des documents originaux du chartrier de l'abbaye de Fécamp pour le Cabinet des Chartes constitué par l'avocat des finances et historiographe Jacob-Nicolas Moreau $(1717-1803)^{128}$. Ce regain d'activité intellectuelle explique la présence actuelle de plusieurs manuscrits médiévaux et modernes à Paris ${ }^{129}$ et à Rouen. Nombre d'entre eux sont sûrement encore à exhumer dans ces fonds et la provenance fécampoise de certains volumes ou fragments reste sans doute à établir.

Toutefois, un grand nombre de manuscrits en possession des moines de Fécamp au moment de la copie de l'inventaire réalisé par dom Abraham Feray avant $1699^{130}$ est resté dans l'abbaye jusqu'à la Révolution. Cet inventaire comporte «seulement» 113 manuscrits médiévaux, ce qui donne une idée très déformée de l'importance de la bibliothèque au temps de sa splendeur et de son apogée: il compte une soixantaine de volumes de moins que la liste partielle dressée à la fin du XII ${ }^{\mathrm{e}}$ siècle ! La bibliothèque devait en effet renfermer au moins le double de volumes manuscrits aux environs de 1550, et peut-être même davantage. La copie partielle de l'exemplaire de dom Feray, réalisée par le collaborateur de Montfaucon, le moine de Saint-Denis dom Le Maître (1692-1740), ne reprend que les 73 premiers

126. NORTIER, 1966, p. 183-184 et 188: «Les religieux de la Congrégation de Saint-Maur y firent affluer des manuscrits de toutes leurs maisons normandes pour la préparation de leurs grandes éditions, en particulier celles des ouvres de saint Ambroise et de saint Grégoire. La plupart fut renvoyée à leurs propriétaires après la fin du travail». Ce ne fut cependant pas le cas d'un grand nombre des manuscrits de Saint-Évroult et de Lyre. Certains manuscrits de Fécamp, aujourd'hui à la bibliothèque municipale de Rouen et non inventoriés par dom Feray dans son catalogue de la fin du XVII ${ }^{e}$ siècle, pourraient faire partie des manuscrits fécampois non restitués par les moines mauristes de Saint-Ouen de Rouen. Geneviève Nortier donne d'ailleurs une liste de manuscrits acquis par Saint-Ouen de Rouen à la fin du XVII ${ }^{\mathrm{e}}$ siècle et dont la provenance et l'origine restent indéterminées ou incertaines (ibidem, p. 189-190).

127. Né à Alençon, il fit profession à Saint-Evroult en 1741 avant de passer à Saint-Germain-des-Prés quelques années plus tard (MATHAN, 1960, p. 255).

128. Ms Paris, BnF, coll. Moreau, 341. Le Comité des chartes avait recruté comme auxiliaires des Bénédictins de la Congrégation de Saint-Maur; dom Lenoir fut chargé des monastères normands. Le Cabinet des Chartes, créé en 1762, fut réuni à la bibliothèque du roi en 1790 (collection Moreau). Voir NORTIER, 1982, p. 173-174; ID., 1960, p. 246; OMONT, 1891, p. V-XIII et 17.

129. Rappelons que la documentation mauriste réunie à Saint-Germain-des-Prés et aujourd'hui conservée à la Bibliothèque nationale de France constitue une mine d'informations sur les anciennes bibliothèques, particulièrement bénédictines, et donc sur Fécamp.

130. Ms Paris, BnF, lat. 13069, fol. 25-43 (cote erronée dans NorTiER, 1957, p. 24 n. 87). Cf. Bibliothèques de manuscrits médiévaux en France, 1987, n582. Le ms Rouen, Bibl. mun., 601 (A. 273), correspondant à la notice F. 44, provient probablement de Fécamp. 
articles de l'inventaire ${ }^{131}$. Bernard de Montfaucon (1655-1741), réagissant à son habitude comme un philologue, donne une idée encore plus réduite du catalogue de Fécamp lorsqu'il utilise ce texte abrégé comme source pour le second volume de la Bibliotheca Bibliothecarum manuscriptorum nova ${ }^{132}$. Après le rachat d'une partie des manuscrits de Mareste en 1699, la bibliothèque de Fécamp comptait donc au moins 127 manuscrits médiévaux à l'aube du XVIII siècle; un nombre vraisemblablement voisin de celui qui aurait dû être recensé lors de l'inventaire des biens et effets réalisé par les officiers municipaux entre le 4 et le 7 mai $1790{ }^{133}$. Les 151 armoires de la bibliothèque renfermaient alors quelque 6555 volumes imprimés ${ }^{134}$. La perte de certains ouvrages, en particulier de livres liturgiques, coïncide avec le départ des 23 moines entre janvier et juin 1791 : une tradition locale veut que les religieux n'aient pas quitté les lieux les mains vides ${ }^{135}$. Ainsi, dom Guillaume-Dominique Le Tellier (1754-1833), maitre de chapelle à l'abbaye de Fécamp, puis curé concordataire de Goderville, a emporté avec lui, outres plusieurs reliques (dont celle du Précieux-Sang), un évangéliaire et un épistolier du XVIII $^{e}$ siècle aujourd'hui conservés au Musée municipal de Fécamp ${ }^{136}$. Toutefois,

131. Ms Paris, BnF, lat. 13074, fol. 210-211 (LM 61). Il contient à la fin la liste des 14 manuscrits acquis de Mareste par Fécamp en 1699. Les numéros 74 à 113, qui concernent principalement des livres théologiques, liturgiques et hagiographiques, n’apparaissent pas dans la copie de dom Le Maître. Sur dom Le Maître et sa Bibliotheca, voir Petitmengin, 1998, p. 540-544, 558-571, 580 (en particulier LM 61 p. 563 et 580). Ce document faisait partie du recueil confié par Montfaucon à dom Le Maître (p. 1991-1993 dans l'ancienne pagination).

132. MontFauCON, 1741, p. 1241-1242; PetitMengin, 1998, p. 537-584 (notamment p. 537 n. 2, 549-554). Montfaucon ne donne que 62 manuscrits ( $n^{\circ} 12$ à 73 ); il omet les manuscrits bibliques $\left(\mathrm{n}^{\circ} 1\right.$ à 11$)$, précisant simplement par une note que les 11 premiers volumes sont des bibles et des commentaires sur les textes sacrés. Il ajoute cependant à la fin 11 des 14 manuscrits obtenus du fils d'Antoine de Mareste en 1699. Nous éditerons le catalogue de dom Feray dans la seconde partie de cet article et étudierons à cette occasion ses rapports avec la copie partielle de dom Le Maître et l'édition abrégée de Montfaucon. Une identification des manuscrits ayant survécu sera également proposée.

133. La mise au propre de l'inventaire, réalisée le 26 mai 1790, a été conservée dans les minutes du Greffe de l'Hôtel de ville de Fécamp: Archives nationales $\mathrm{F}^{19} 611^{\mathrm{c}}$ (document reproduit dans MONTIER, 1960, p. 17-96, appendice I p. 47-80). On y apprend que la bibliothèque du monastère était alors "composée d'armoires en chaîne qui présentent cent cinquante [et] une cases toutes remplies de livres portant différents intitulés in $\mathrm{f}^{\circ}$, in $4^{\circ}$, in $8^{\circ}$, in $12^{\circ}$, au nombre d'environ six mil six cents observant que la première armoire à gauche contre la croisée qui donne sur la cour est remplie de manuscrits» (ibidem, p. 75 ; voir aussi La bibliothèque imprimée, 2001, p. 5 ; ROUET, 2005, p. 23). Elle ne précise malheureusement pas leur nombre!

134. La bibliothèque imprimée, 2001, p. 5.

135. Selon André-Paul Leroux, Conservateur des Musées de Fécamp entre 1931 et 1950, les moines, imaginant pouvoir revenir rapidement dans leur abbaye, auraient remis (plutôt qu'emporté avec eux) des documents et objets précieux à des particuliers de la cité. Certains d'entre eux les auraient ensuite soit revendus à Alexandre Le Grand $(† 1895)$ pour son Musée de la Bénédictine (la recette de la Bénédictine, figurant dans un manuscrit de Fécamp, lui serait d'ailleurs parvenue par héritage), soit offerts au Musée municipal de la ville.

136. Ces deux manuscrits furent légués par ses soins au docteur Robin; le fils de celui-ci en fit don au notaire de Caudebec-en-Caux Maître Georges Biochet (bibliophile dont la collection fut dispersée aux enchères au Havre le 19 janvier 1942), qui les légua à son successeur, Maître Le Courtois, 
des vols ont sans doute aussi été perpétrés suite à la fermeture définitive du monastère en juin 1791 et avant l'entrée des livres dans leur fonds définitif. Le Musée de la Bénédictine conserve au moins une douzaine de manuscrits emportés à l'occasion de ces événements ${ }^{137}$. De nombreux documents originaux provenant du chartrier de Fécamp - chartes, vidimus, lettres, etc. - acquis par le Musée de la Bénédictine en 1901 proviennent d'une succession d'héritages forts obscures. Il en est de même pour une partie des papiers des moines mauristes réunis sous le $\mathrm{n}^{\circ} 207$ dans le catalogue du musée dressé en $1888^{138}$. Le marquis Louis-Augustin Le Ver, membre de la Société des antiquaires de Normandie et de l'Académie de Rouen, semble avoir lui aussi obtenu des manuscrits au cours de ces circonstances fort troublées ${ }^{139}$.

En octobre 1791, Philippe François Gourdin - ancien moine de Saint-Ouen de Rouen, employé depuis comme commissaire du Directoire du département s'arrêta durant six jours à Fécamp lors de sa tournée des communautés religieuses supprimées de la Seine-Inférieure ${ }^{140}$. Il était chargé de prélever dans ces établissements

en lui recommandant de les offrir au Musée de Fécamp : les manuscrits y sont à présent conservés. Dom Laurent-François Bardel (1763- apr.1840), professeur et bibliothécaire, pourrait avoir lui aussi emporté quelques livres. Cf. LECROQ, 1935, p. 19-23; CHAUSSY, 1959, p. 255, 265-266; MONTIER, 1960, p. 28 et 334-336 n. 79; ID., 1961, p. 134-135 et 152-153; ENGEL, 1960, p. $297-$ 321. Je tiens à remercier Marie-Hélène Desjardins, Conservateur en chef du Musée de Fécamp, qui m’a communiqué les renseignements de la présente note, ainsi que de la précédente.

137. L'Ordinaire de l'abbaye (XIII ${ }^{\mathrm{e}}$ siècle; n 186 du catalogue de 1888), l'Epistolier et l'Évangéliaire du prieur Charles Campion ( $\left.1600 ; n^{\circ} 208\right)$, ainsi que plusieurs manuscrits et livres d'heures sont aujourd'hui conservés dans le Musée de la Bénédictine (ENGEL, 1960, p. 302-318). Toutefois, selon Dominique Rouet, conseiller scientifique participant au projet de nouvel espace pour améliorer les conditions d'exposition et qui a de ce fait examiné l'ensemble des imprimés en 2001, les deux bibliothèques que le Musée présente encore aujourd'hui comme vestiges des fonds de l'abbaye regroupent un millier de volumes imprimés qui ne portent aucunement l'ex-libris de Fécamp (seuls quelques-uns portent cette marque de propriété); de provenances diverses, ils ont été réunis par Alexandre Le Grand et n’ont aucun rapport avec Fécamp ! Nous remercions Dominique Rouet pour ces intéressantes précisions. Quelques volumes figurent toujours dans des collections privées: c'est en particulier le cas des 76 cahiers de dom Lenoir (partie normande de l'enquête pour les Collections sur l'histoire des provinces) microfilmés en 1954-1955 par les Archives nationales et dont 3 cahiers au moins concernent Fécamp (NORTIER, 1982, p. 174; MATHAN, 1960, p. 255-274).

138. Il reste sans doute quelques pièces intéressantes à exhumer dans ce lot de quelque 160 pièces.

139. Le ms Paris, BnF, nouv. acq. lat. 2412 provient de la collection du marquis Le Ver : il figure dans le catalogue des ventes de sa bibliothèque (1866), et a été acquis par sir Thomas Phillipps, puis par la Bibliothèque nationale de France en 1908; le ms Paris, BnF, nouv. acq. fr. 10670, également fécampois, pourrait avoir suivi le même cheminement (OMONT, 1909, p. I-XI, 88-89 et 109; NORTIER, 1960, p. 245). Sur Louis-Augustin Le Ver, descendant de Firmin Le Ver (1375-1444), voir http://www.chass.utoronto.ca/edicta/shaw/a256.htm.

140. Accompagné du peintre rouennais Le Carpentier, il inspecta 22 établissements entre le 22 septembre et le $1^{\text {er }}$ novembre 1791 : Gournay-en-Bray, Beaubec, Foucarmont, Auchy-lès-Aumale, Eu, Le Tréport (abbaye), Dieppe (Capucins, Carmes et Minimes), Longueville-sur-Scie, Capucins de Veules, Pénitents de Saint-Valéry, Valmont, Fécamp (abbaye et Capucins), Le Havre (Capucins du Havre et d'Ingouville; chanoines réguliers de Sainte-Honorine de Graville), Le Valasse, Caudebec 
les manuscrits, livres et œuvres d'arts jugés intéressants pour les regrouper dans le dépôt littéraire du chef-lieu de département. Les documents saisis nécessitèrent trois voitures pleines qui furent aussitôt envoyées à Rouen dans l'ancien couvent des Jacobins, où inventaires et classements devaient être bientôt réalisés ${ }^{141}$. Quelques années plus tard, malgré le décret du 27 janvier 1794 ( 8 pluviôse an II) stipulant l'établissement d'une bibliothèque publique dans chaque district pour l'instruction du peuple, la bibliothèque des moines de Fécamp ne fut que partiellement restituée au district de Montivilliers ${ }^{142}$ : il semblerait que dom Gourdin, conservateur du dépôt littéraire de Rouen puis premier bibliothécaire de cette ville, se soit contenté de réexpédier la majorité des livres imprimés, et qu'il ait précieusement conservé les manuscrits de l'abbaye, ne se résignant pas à les voir partir ; il opéra visiblement de la même manière avec des codices de diverses autres provenances $^{143}$. Les volumes fécampois prélevés par Gourdin en 1791 sont de ce fait aujourd'hui principalement conservés à la Bibliothèque municipale de Rouen pour les manuscrits, à la Bibliothèque municipale du Havre pour les imprimés et dans le fonds $7 \mathrm{H}$ des Archives départementales de la Seine-Maritime pour les documents provenant de l'ancien chartrier de l'abbaye ${ }^{144}$. Ainsi, les troubles révolutionnaires, les spoliations des biens ecclésiastiques et les applications plus ou moins

(Capucins et Feuillants d'Ouville-l'Abbaye) et Saint-Wandrille. Trois établissements importants ne furent pas visités: Jumièges (encore occupé par les moines), Montivilliers et l'ancien collège des Jésuites du Tréport (tenu par les Oratoriens). Dubuc, 1979, p. 150-151; voir aussi La bibliothèque imprimée, 2001, p. 2, 5-6.

141. Sur ces événements, voyez Dubuc, 1979, p. 141-155. Le Musée municipal de Fécamp conserve, sous le titre Cathalogue universel de tous les livres de la bibliothèque de la ci-devant abbaye de Fécamp, 1791 le catalogue des livres imprimés rédigé à ce moment-là : ms Fécamp, Bibl. Mun., 21. Tout laisse penser que les commissaires de la Révolution avaient également rédigé un catalogue des manuscrits, mais celui-ci n'a pu être retrouvé à ce jour. En effet, les notes ajoutées à l'encre noire sur les premiers feuillets de certains manuscrits conservés à Rouen proviennent sans doute des inventaires réalisés à cette occasion : une main moderne a indiqué la provenance du ms, reproduit le titre du catalogue, ainsi que la cote que l'on retrouve dans la copie de l'inventaire réalisé par dom Feray. Il reste à espérer que l'on pourra un jour remettre la main sur cette pièce importante pour notre connaissance de la dispersion des manuscrits de la bibliothèque de Fécamp.

142. Les livres furent d'abord envoyés à Montivilliers, chef-lieu de district, avant d'être apportés au Havre, ville finalement choisie en raison de sa population importante pour y établir la bibliothèque publique du district (elle ouvre ses portes en avril 1800). Durant ces transferts, de nouveaux vols ont été perpétrés (cf. NORTIER, 1957, p. 25 ; La bibliothèque imprimée, 2001, p. 2, 5-6). Un catalogue des livres imprimés de la bibliothèque de Fécamp envoyés à la bibliothèque du Havre fut dressé dès 1794 : le ms Le Havre, Bibl. mun., 900 comporte 2061 titres, mais ce nombre doit être largement majoré quant au nombre réel de volumes (La bibliothèque imprimée, 2001, p. 15). Une liste des livres composant la bibliothèque du Havre en 1799 figure dans le ms Paris, BnF, nouv. acq. Fr. 5317 (NORTIER, 1960, p. 247).

143. VARRY, 1991, p. 14; RICHARD, 1991, p. 44-45. Merci à Dominique Rouet pour les nombreuses précisions qu'il a pu m'apporter sur la dispersion de la bibliothèque de Fécamp lors de la Révolution. Voir aussi Rouet, 2005, p. 22 col. b et 25 col. b.

144. Par la loi du 5 brumaire an V (1797), les titres et papiers des établissements religieux devaient désormais être regroupés dans des archives centralisées au niveau des chefs-lieux des départements. BLANCHET, 1960, p. 241-243. 
rigoureuses des décrets votés de 1790 à 1797 ont contribué aux ultimes dispersions des livres de Fécamp ${ }^{145}$ : dès octobre 1791 la bibliothèque monastique n'existe plus et l'abbaye est vendue le 20 septembre de l'année suivante ${ }^{146}$.

\section{Conclusion}

Au terme de cette enquête, six vagues de dispersion des fonds de la bibliothèque de Fécamp, de natures et d'importances variées, ont pu être mises en évidence depuis le milieu du XVI e et jusqu'à la fin du XVIII e siècle (voir le diagramme $\left.{ }^{\circ} 1\right)^{147}$ :

- la première, imputable aux pillages huguenots au cours de la première guerre de Religion, doit être placée en 1562-1563. Les textes classiques et historiques étaient visiblement les principales œuvres convoitées. Il semblerait que la famille de Coligny ait joué un rôle non négligeable dans la dispersion des manuscrits fécampois et normands: le cardinal Odet de Coligny et ses frères pourraient en effet avoir personnellement approvisionné Pierre Daniel (15311604) et Philippe Hurault de Cheverny (1527-1594), les deux seuls collectionneurs de la seconde moitié du XVI ${ }^{e}$ siècle pour lesquels la possession de manuscrits de Fécamp est aujourd'hui bien établie. Pierre Daniel est de son côté connu pour avoir fourni des manuscrits et des recueils factices à son ami Pierre Pithou (1539-1596), humaniste et philologue appartenant à un réseau de collectionneurs gravitant autour du Parlement de Paris. Après diverses vicissitudes, ce sont les bibliothèques de Paris, du Vatican, de Berne et de Leyde qui conservent aujourd'hui les plus importants vestiges de ces pillages huguenots, mais d'autres bibliothèques d'Europe sont également concernées;

- la seconde est imputable au cardinal François de Joyeuse, abbé commendataire de Fécamp (1603-1615) et archevêque de Rouen (1604-1615). Elle explique le passage de deux manuscrits historiques fécampois - ainsi sans doute que de plusieurs autres manuscrits normands et français - dans la bibliothèque du Collège de Clermont au début du XVIIe siècle, puis dans les collections privées de Gérard Meermann (1722-1771) et de sir Thomas Phillipps (17921872), avant d'intégrer la Bibliothèque royale de Berlin en 1887 ;

145. Si la loi avait été pleinement exécutée, c'est au Havre et non pas à Rouen que les manuscrits de Fécamp devraient aujourd'hui se trouver, avec le reste de la bibliothèque des moines de Fécamp.

146. Trois adjudications furent nécessaires: les deux premières, réalisées les 22 mars et 13 juin 1792, frappées de folles enchères, n'avaient pu aboutir (MONTIER, 1960, p. 44).

147. Il est difficile d'évaluer l'ampleur des deux premières vagues de dispersion, notamment du fait de démembrements de manuscrits et de la constitution de recueils factices (de tels remaniements ont été moins fréquents lors des vagues de dispersion ultérieures) : les bibliothèques du Vatican, de Leyde, de Berne, de Berlin et de Paris (notamment) conservent certainement des fragments fécampois (et normands) non encore identifiés à ce jour. 
- la troisième - correspondant à une vente probablement réalisée entre 1614 et 1617 par le grand prieur de Fécamp Charles Campion (1614-1639) - paraît avoir eu le Doyen de la Cour des Aides de Normandie, Jean Bigot (1593-1653), pour unique bénéficiaire. C'est la dispersion la mieux connue et, semble-t-il, la plus considérable, avec 56 manuscrits identifiés à ce jour - dont un grand nombre de recueils d'œuvres patristiques, théologiques et hagiographiques des $\mathrm{XI}^{\mathrm{e}}$ et XII ${ }^{\mathrm{e}}$ siècles - conservés à Paris dans le fonds latin de la Bibliothèque nationale de France;

- la quatrième, bien qu'à son apogée dans les années 1640, s’est échelonnée sur au moins trente ans, de 1630 à 1660 : il s'agit d'acquisitions ponctuelles de manuscrits réalisées par Jacques et Antoine de Mareste, sans doute dans le but de composer une Histoire de l'abbaye de Fécamp. De 20 à 50 manuscrits, aujourd'hui conservés à la Bibliothèque municipale de Rouen, à la Bibliothèque nationale de France et au Musée de la Bénédictine de Fécamp, ont fait l'objet de ces prélèvements périodiques qui mériteraient une étude approfondie ;

- une cinquième vague concerne la «période mauriste» de l'abbaye: réformée en 1650 par la Congrégation de Saint-Maur, les moines bénédictins ont transmis quelques originaux, mais surtout des copies de manuscrits à leur maison mère établie à Saint-Germain-des-Prés, ainsi qu'au centre d'études de SaintOuen de Rouen: le but était de fournir - principalement dans la seconde moitié du XVII ${ }^{\mathrm{e}}$ siècle - les sources aux grandes entreprises littéraires mauristes, en particulier patristiques, théologiques et historiques. Les fonds de ces deux abbayes furent respectivement transférés à la Bibliothèque nationale de France en 1795 et au dépôt littéraire de Rouen en 1790, où des documents fécampois sont sans doute aujourd'hui encore à exhumer ;

- enfin, une sixième et dernière vague de dispersion eut lieu pendant la Révolution: si la perte de certains livres liturgiques est due au départ des moines dans le premier semestre de l'année 1791, celle de plusieurs volumes, notamment historiques, s'explique par des vols effectués après la fermeture de l'abbaye et avant l'arrivée des manuscrits à Rouen dans le second semestre de cette même année. On retrouve aujourd'hui principalement ces manuscrits et chartes aux Archives départementales de la Seine-Maritime, à la Bibliothèque municipale de Rouen et dans les Musées de Fécamp. Mais certains volumes pourraient toujours figurer dans quelques collections privées locales...

Parvenir à définir le contenu d'une bibliothèque médiévale disséminée à travers l'Europe, c'est tenter de reconstituer intellectuellement la mémoire d'une communauté et un patrimoine culturel aujourd'hui difficilement perceptible, tout en gardant les codices dans leurs lieux de conservation actuels. Dans le cas de Fécamp, il s'agit d'un patrimoine de premier ordre puisque ce monastère bénédictin est à compter parmi les plus importantes abbayes médiévales: premier établissement normand réformé selon la règle de saint Benoît par Guillaume de Volpiano après l'an Mil, l'abbaye fut le point de départ d'un grand nombre de restaurations monastiques 
ultérieures en Normandie; sa grandeur était reconnue bien au-delà des frontières du duché, d'abord dans les régions voisines ${ }^{148}$, mais aussi hors du continent, puisque les liens artistiques et intellectuels avec l'Angleterre avant et après la conquête de 1066 furent nombreux ${ }^{149}$. Si la Commende, les guerres de Religion et la Révolution favorisèrent la fuite des livres et l'éparpillement des manuscrits, l'abbaye de Fécamp dispose malgré tout d'un excellent taux de conservation de ses anciens fonds ${ }^{150}$. Il reste d'ailleurs assurément des documents à exhumer, en particulier aux Archives départementales de la Seine-Maritime, aux Archives nationales de France et dans les anciens fonds mauristes de Saint-Germain-des-Prés aujourd'hui conservés à la Bibliothèque nationale de France et au Musée de la Bénédictine. L'établissement d'un catalogue ${ }^{151}$, où chaque manuscrit bénéficierait d'une notice détaillée, permettrait non seulement de rassembler les descriptions de tous les codices identifiés à ce jour comme ayant appartenu à l'ancienne abbaye bénédictine de Fécamp, mais aussi de faciliter les travaux de recherche pour retrouver des manuscrits et des fragments de même provenance, disséminés dans les bibliothèques d'Europe, notamment dans des recueils factices et des membra disiecta ${ }^{152}$. Ce catalogue aurait également pour vocation de définir un ensemble de critères paléographiques et codicologiques permettant d'identifier un manuscrit issu du scriptorium de Fécamp ou ayant appartenu à cette abbaye ${ }^{153}$. Les mains des scribes et des lecteurs

148. À ce sujet, les témoignages du chanoine Dudon de Saint-Quentin (X-XIe siècle), du moine bourguignon Raoul Glaber (XIe siècle) et de l'archevêque de Dol Baudri de Bourgueil (XII ${ }^{e}$ siècle) nous paraissent significatifs; l'attention des papes portée à l'abbaye à la fin du XII ${ }^{e}$ siècle est également éloquente. La Trinité de Fécamp était alors un centre de pèlerinage important grâce à la relique du Précieux Sang; elle était également fort riche grâce à ses possessions en terres et à de nombreux privilèges (BEAUREPAIRE, 1859, p. 153-155; NorTiER, 1957, p. 8-9; GAZEAU, 2002, p. 35-36, 38 ; GreEN, 2002, p. 12 et p. 16; BOUET, 2002, p. 57-70; TrÂN-DuC, 2006, p. 533).

149. L'origine de nombreux manuscrits importés de Normandie en Angleterre aux XI ${ }^{e}$ et XII ${ }^{e}$ siècles reste à établir : une liste préliminaire a été réalisée par Michael Gullick pour les cathédrales de Cantorbéry (Christ Church), de Durham, d'Exeter, de Worcester ainsi que pour Saint-Paul de Londres, Saint-Augustin de Cantorbéry et le monastère de Malmesbury (GULLICK, 2005, p. 92-93); le rôle de Fécamp dans la transmission de certains textes, perceptible dans des lieux tels que les cathédrales d'Exeter et de Durham, reste à évaluer (GAMESON, 2005, p. 120 et 122). Voir aussi D.H.G.E.

150. L'exceptionnelle documentation conservée sur cette abbaye a été signalée par Jacques Dubois: elle lui a permis de restituer une partie du martyrologe primitif d'Usuard, tout en étudiant la méthode de travail d'un copiste du XII ${ }^{e}$ siècle (DubOIS, 1977, p. 58 et 71).

151. Ce souhait était déjà formulé par Geneviève Nortier il y a plus de 50 ans (NorTIER, 1957, p. 1). Afin de faciliter ce travail, nous proposons de publier prochainement, dans cette même revue, un tableau synthétique des œuvres (auteurs et titres) présentes à Fécamp, avec leurs références dans les inventaires des $\mathrm{XI}^{\mathrm{e}}$-XVIII ${ }^{\mathrm{e}}$ siècles, ainsi que leurs cotes dans les fonds anciens et modernes.

152. Ainsi, l'espoir de retrouver un jour dans l'une de ces bibliothèques des fragments des textes classiques et historiques mentionnés dans les catalogues de Fécamp des XI ${ }^{e}$ et XII ${ }^{e}$ siècles pour lesquels aucune identification n'a pu être proposée n'est pas complètement perdu (par exemple: l'Enéïde de Virgile dont Pierre Daniel fut l'éditeur, les Topiques d'Aristote, le Somnium Scipionis de Cicéron, la Hiérarchie céleste de Denis l'Aéropagite, la Consolation de Philosophie de Boèce, l'Histoire tripartite de Cassiodore, l'Histoire d'Orose, l'Histoire scolastique de Pierre le Mangeur, le De Trinitate d'Alcuin, etc.).

153. Les nouveaux procédés de recherche devront être exploités à cette occasion. Les travaux de Claude Coupry sur les pigments utilisés pour l'enluminure à Fécamp aux XI ${ }^{\mathrm{e}}$ et XII ${ }^{\mathrm{e}}$ siècles ont déjà 
responsables d'ex-libris, de tables de contenu et de diverses autres annotations caractéristiques mériteraient une attention particulière ${ }^{154}$. Il reste à espérer que ce travail passionnant et de longue haleine saura mobiliser les moyens indispensables à sa réalisation. Un travail d'ailleurs facilité par les travaux antérieurs de nombreux chercheurs, ainsi que par l'existence d'une riche tradition textuelle, comme en témoigne l'importante bibliographie qui suit.

\section{Bibliographie $^{155}$}

L'Abbaye bénédictine de Fécamp. Ouvrage scientifique du XIII centenaire (658-1958), Jehan Le Povremoyne (dir.), Fécamp, L. Durand et fils, 1959-63, 4 vol. (xx-410, 390, 304 et 165 p).

ARNOUX, Mathieu, «La fortune du Libellus de Revelatione, edificatione et auctoritate fiscannensis monasterii ", Revue d'Histoire des Textes, 21, 1991, p. 135-158.

ID., «Before the Gesta Normannorum and Beyond Dudo: Some Evidence on Early Norman Historiography ", Anglo-Norman Studies, 22, 1999, p. 29-48.

Aubert, Hippolyte, «Notices sur les manuscrits Petau, conservés à la Bibliothèque de Genève », Bibliothèque de l'École des Chartes, 70, 1909, p. 247-302 et p. 471-522 (Gallica/BnF).

ID., "Notices sur les manuscrits Petau, conservés à la Bibliothèque de Genève (suite)", Bibliothèque de l'École des Chartes, 72, 1911, p. 279313 et p. 556-599 (Gallica/BnF).

\footnotetext{
. permis de collecter de précieux renseignements (COUPRY, 2005, p. 69-79). Une étude des reliures fécampoises reste à entreprendre (voir toutefois LAFFITTE, 2005, p. 199) : les mss Paris, BnF, lat. 2405, Rouen, Bibl. mun., 41, 292, 294 et 1388 se révéleront alors sans doute déterminants (reliures sur ais de bois avec traces de fermoirs); il en est peut-être de même pour les manuscrits « à reliure peau blanche» décrits dans le catalogue d'Henri Omont (reliures sur ais de bois d'époque médiévale tardive). Enfin, la mise en lumière par Maylis Baylé (BAYLÉ, 2005, p. 65-66) des rapports existant entre les enlumineurs et les sculpteurs vers 1100 est également un domaine prometteur à explorer. Les quelques champs d'étude, exposés brièvement ici, sont évidemment loin d'être exhaustifs.

154. Ce catalogue devra notamment mettre en application les dernières méthodes d'analyse et de description présentées dans l'ouvrage de référence Lire le manuscrit médiéval; les méthodes de travail sur les bibliothèques anciennes développées depuis plusieurs années par les chercheurs de l'IRHT, tels que A. Vernet, M.-H. Jullien de Pommerol, A. Bondéelle, M.-L. Auger, D. Muzerelle et F. Dolbeau, devront également être mises à profit ; ce catalogue pourrait être intégré dans un volume plus général, en s'inspirant des travaux de la collection Documents, Études et Répertoires relative à l'histoire des bibliothèques médiévales, tel que le volume de M. Peyrafort-Huin sur La bibliothèque médiévale de l'abbaye de Pontigny.

155. Les références bibliographiques suivies de la mention «(Gallica/BnF) et (Persée) » signalent des ouvrages numérisés sur les sites Gallica (http://gallica.bnf.fr/) et Persée (http://www.persee.fr/).
} 
Voir aussi http://www.geneva-city.ch/bpu/manusc/f/ catalogue_ms_1_198.pdf

AVRIL, François, «Supplément à la liste des manuscrits des bibliothèques étudiées », Revue Mabillon, 210, 1962, p. 182-183.

ID., La décoration des manuscrits dans les abbayes bénédictines de Normandie au XI ${ }^{e}$ et XII ${ }^{e}$ siècles, thèse inédite de l'École des Chartes, Paris, 1963 (résumé dans École des chartes, Positions des thèses, 1963, p. 21-28).

ID., «Notes sur quelques manuscrits bénédictins normands du $\mathrm{XI}^{\mathrm{e}}$ et du XII siècle ", Mélanges d'Archéologie et d'Histoire, 76, 1964, p. 491525 (Persée).

ID., «Notes sur quelques manuscrits bénédictins normands du $\mathrm{XI}^{\mathrm{e}}$ et du XII ${ }^{\mathrm{e}}$ siècle (suite) », Mélanges d'Archéologie et d'Histoire, 77, 1965, p. 209-248 (Persée).

ID., "La décoration des manuscrits au Mont Saint-Michel (XI ${ }^{\mathrm{e}}$-XII ${ }^{\mathrm{e}}$ siècles). Appendice: Les rapports artistiques entre Fécamp et le Mont SaintMichel », in Millénaire monastique du Mont Saint-Michel, t. II, Raymonde ForeVILLE (dir.), Paris, Lethielleux, 1967, p. 235-238.

BALAYÉ, Simone, "La bibliothèque du roi, première bibliothèque du monde (1664-1789)", in Histoire des bibliothèques françaises, t. II, Les bibliothèques sous l'Ancien Régime (1530-1789), Claude JOLLY (dir.), Paris, Promodis, 1988, p. 209-233.

BATES, David, Normandy before 1066, Londres, Longman, 1982, XX-287 p.

BAYLÉ, Maylis, "Architecture et enluminure dans le monde normand ", in Manuscrits et enluminures dans le monde normand ( $X^{e}-X V^{e}$ siècle), Actes du colloque de Cerisy-la-Salle (octobre 1995), Pierre BOUET et Monique Dosdat (dir.), Caen, Presses universitaires de Caen, 2005, p. 51-68.

Beaurepaire (de), Charles, "Anciens inventaires du trésor de l'abbaye de Fécamp ", Bibliothèque de l'École des Chartes, 20, 1859, p. 153170 et p. 399-411 (Gallica/BnF).

BERgER, Élie, "Pierre Daniel et ses amis », Bibliothèque de l'École des Chartes, 46, 1885, p. 717-718 (Gallica/BnF).

Bibliothèques de manuscrits médiévaux en France: relevé des inventaires $d u$ VIII ${ }^{e}$ au XVIII ${ }^{e}$ siècle, Anne-Marie GENEVOIS, Jean-François GENEST et Anne Chalandon (éd.), Paris, Centre national de la recherche scientifique, 1987, XIX-388 p. 
Bibliothèque imprimée de l'abbaye de Fécamp (la), Exposition 8 septembre-10 novembre 2001 dans le cadre du millénaire de l'abbaye bénédictine de Fécamp, 16 p. (brochure).

BiBOLET, Françoise, «Bibliotheca Pithoeana, les manuscrits des Pithou: une histoire de fraternité et d'amitié», in Du copiste au collectionneur, Mélanges d'histoire des textes et des bibliothèques en l'honneur d'André Vernet, textes réunis par Donatella NEBBIAI-DALla GUARDA et Jean-François GENEST, Turnhout, Brepols, 1998 (Bibliologia, 18), p. 497-521.

BLANCHET, François, "Le chartier de l'abbaye de Fécamp », in L'Abbaye bénédictine de Fécamp. Ouvrage scientifique du XIII centenaire (6581958), t. II, Jehan Le Povremoyne (dir.), Fécamp, L. Durand et fils, 1960, p. 241-243.

BLOCH, Denise, «La bibliothèque de Colbert », in Histoire des bibliothèques françaises, t. II, Les bibliothèques sous l'Ancien Régime (15301789), Claude Jolly (dir.), Paris, Promodis, 1988, p. 157-180.

Bouet, Pierre, «Dudon de Saint-Quentin et Fécamp », Tabularia «Études», $\mathrm{n}^{\circ} 2,2002$, p. 57-70.

Bougard, François, Histoire des Lombards de Paul Diacre, Turnhout, Brepols (Miroir du Moyen Âge), 1994.

Bouquet, François, «Hugues de Groot correspondant de Claude Sarrau à Rouen ", Mélanges de la Société de l'Histoire de Normandie, I, 1891, p. 95-114.

ID., « Lettres de Claude Sarrau écrites à Rouen pendant l'interdiction de son parlement ", Mélanges de la Société de l'Histoire de Normandie, I, 1891, p. 115-154.

Bourgain, Pascale, "Ademari Cabannensis Chronicon», in Ademari Cabannensis Opera Omnia, Turnhout, Brepols (Corpus Christianorum. Continuatio Medieualis, CXXIX), 1999, CXVI- 362 p.

Boutemy, Alain, « K. A. De Meyer - Paul en Alexandre Petau en de geschiedenis van hun handschriften. Leyde, E. J. Brill, 1947 », Scriptorium, 4, 1, 1950, p. 168-171.

BRANCH, Betty, The development of script in Eleventh and Twelfth Century Manuscripts of the Norman Abbey of Fecamp, Ann Arbor (Michigan), Bell and Howell Information Company, 1974.

ID., "Inventories of the Library of Fécamp from the Eleventh and Twelfth Century», Manuscripta, 23, 1979, p. 159-172.

ID., «Willermus Peccator et les manuscrits de Fécamp 1100-1150», Cahiers de civilisation médiévale, 26, 1983, p. 195-207. 
BRUYNE (de) (dom), «Membra disjecta », Revue bénédictine, 37, 1925, p. 166-169.

Catalogue des manuscrits en écriture latine portant des indications de date, de lieu ou de copiste, t. VII, Ouest de la France et Pays de Loire, Robert MARICHAL (dir.), Paris, Centre national de la recherche scientifique, 1985, p. XXI.

Catalogue général des manuscrits latins de la Bibliothèque nationale, Paris, t. I, n 1-1438, 1939, t. II, n 1439-2692, 1940, t. III, n²693-3013A, 1952 , t. IV, n 3014-3277, 1958, t. V, n ${ }^{\circ} 3278-3535,1966$, t. VI, $\mathrm{n}^{\circ} 3536-3775 \mathrm{~B}, 1975, \mathrm{t}$. VII, n 3536 à $3775 \mathrm{~B}, 1988$ + tables des t. I- II, 1968, t. III-VI, 1981, t. VII, 1991 (Gallica/BnF).

Catalogus codicum manuscriptorum Bibliothecae regiae, $\mathrm{n}^{\circ}$ 4794-8844, Paris, 1744 (Gallica/BnF).

Catholicisme: hier, aujourd'hui, demain, Paris, Letouzey et Ané, 19472000,15 vol.

CHAPLAIS, Pierre, «Une charte originale de Guillaume le Conquérant pour l'abbaye de Fécamp : la donation de Steyning et de Bury (1085) », in L'Abbaye bénédictine de Fécamp, t. I, 1959, p. 93-104 et p. 355-357.

Chaussy, Yves (dom), «Les derniers moines de Fécamp: notes et documents", in L'Abbaye bénédictine de Fécamp. t. I, 1959, p. $253-$ 266 et p. 407.

Chibnall, Marjorie, "Fécamp and England/Fécamp et l'Angleterre», in L'Abbaye bénédictine de Fécamp. Ouvrage scientifique du XIII centenaire (658-1958), t. I, 1959, p. 127-135 et p. 363-378.

Codices Vossiani latini, Karel Adriaan de MEYIER (dir.), Leyde, Universitaire Pers Leiden, 1973-1984, 4 vol. (xvi-261, 292, 193 et 160 p.)

CORON, Antoine, «Ut prosint aliis: Jacques-Auguste de Thou et sa bibliothèque ", in Histoire des bibliothèques françaises, t. II, Les bibliothèques sous l'Ancien Régime (1530-1789), Claude Jolly (dir.), Paris, Promodis, 1988, p. 101-125.

COUPRY, Claude, «Les pigments utilisés pour l'enluminure à Fécamp aux XI ${ }^{e}$ et XII ${ }^{e}$ siècles », in Manuscrits et enluminures..., 2005, p. 69-79.

DAOUST, Joseph (abbé), «La réforme mauriste à Fécamp (31 décembre 1649) », in L'Abbaye bénédictine de Fécamp, t. I, 1959, p. 193-201 et p. 389-390.

ID., "Les mauristes à Fécamp de 1650 au début du XVIII ${ }^{e}$ siècle ", in L'Abbaye bénédictine de Fécamp, t. I, 1959, p. 203-218 et p. 391-397. 
ID., «Dom Filipe Le Cerf de la Viéville, critique et historien (16771748) », in L'Abbaye bénédictine de Fécamp, t. I, 1959, p. 229-252 et p. 401-405.

DELISLE, Léopold, "Cérémonial d'une épreuve judiciaire », Bibliothèque de l'École des Chartes, 18, 1857, p. 253-255 (Gallica/BnF).

ID., Le Cabinet des Manuscrits de la bibliothèque nationale, t. I, Paris, Imprimerie nationale, 1868 , p. 285-289, 322-329, 455 et 524-575 (cf. http://ccfr.bnf.fr/rnbcd_visu/FondetailServlet?NoList=1\&num =966).

ID., «État des manuscrits de la Bibliothèque nationale au $1^{\text {er }}$ août 1871 », Bibliothèque de l'École des Chartes, 32, 1871, p. 20-62 (Gallica/BnF).

ID., "Notice sur vingt manuscrits du Vatican ", Bibliothèque de l'École des Chartes, 37, 1876, p. 472-527 (Gallica/BnF).

ID., Bibliotheca Bigotiana manuscripta: catalogue des manuscrits rassemblés au XVII siècle par les Bigot, mis en vente au mois de juillet 1706, aujourd'hui conservés à la Bibliothèque Nationale, Rouen, Boissel, 1877, XXXII-105 p. (Gallica/BnF).

Voir aussi : http://elec.enc.sorbonne.fr/cataloguevente/notice64.php.

ID., «Matériaux pour l'édition de Guillaume de Jumièges préparée par Jules Lair: préface de Léopold Delisle», Bibliothèque de l'École des Chartes, 71, 1910, p. 481-526 (Gallica/BnF).

Delivré, Fabrice, «Les chroniques de Saint-Pierre-le-Vif au miroir de la primauté sénonaise: enquête sur les manuscrits d'Odorannus, du pseudo-Clarius et de Geoffroy de Courlon », Bibliothèque de l'École des Chartes, 163, 2, 2006, p. 481-503.

DOLBEAU, François, «Notes sur la genèse et sur la diffusion du Liber de Natalitiis », Revue d'Histoire des Textes, 6, 1976, p. 143-195 (en particulier p. 150 n. $\left.2,154 \mathrm{n}^{\circ} 14,155 \mathrm{n}^{\circ} 17,161 \mathrm{n}^{\circ} 25\right)$.

ID., «Anciens possesseurs des manuscrits hagiographiques latins conservés à la Bibliothèque nationale de Paris", Revue d'Histoire des Textes, 9, 1979, p. 183-238.

ID., « Typologie et formation des collections hagiographiques d'après les recueils de l'abbaye de Saint-Thierry ", in Saint-Thierry: une abbaye du $V^{e}$ au XXe siècle, Actes du colloque international d'histoire monastique (Reims-Saint-Thierry, 11 au 14 octobre 1976), Saint-Thierry, Association des Amis de l'Abbaye de Saint-Thierry, 1979, p. 159-182.

Douglas, David, "The first ducal charter for Fécamp/La première charte ducale pour Fécamp ", in L'Abbaye bénédictine de Fécamp..., t. I, 1959, p. 45-56 et p. 323-339. 
DuboIs, Jacques «À la recherche de l'état primitif du martyrologe d'Usuard: le manuscrit de Fécamp ", Analecta Bollandiana, 95, 1977, p. 43-71.

DuBuC, André, «La nouvelle règle intérieure établie à l'abbaye de Fécamp en 1618 », in L'Abbaye bénédictine de Fécamp. Ouvrage scientifique du XIII ${ }^{e}$ centenaire (658-1958), t. I, Jehan LE POVREMOYNE (dir.), Fécamp, L. Durand et fils, 1959, p. 181-188 et 387.

ID., "Quelques plans concernant l'abbaye de Fécamp », in L'Abbaye bénédictine de Fécamp, t. III, 1961, p. 121-128 et p. 265.

ID., «Bibliothèques et œuvres d'art dans les abbayes supprimées à la Révolution en Seine-Inférieure ", in Les abbayes de Normandie, Actes du XIII ${ }^{e}$ congrès des sociétés historiques et archéologiques de Normandie, Rouen, Lecerf, 1979, p. 141-155.

Enluminures, base de données des manuscrits médiévaux enluminés conservés dans les bibliothèques municipales: http://www.enluminures.culture.fr/.

ENGEL, René-Émile, «Le musée de la société bénédictine et ses souvenirs abbatiaux", in L'Abbaye bénédictine de Fécamp, t. II, 1960, p. 297-321 et p. 389-390.

Fauvel, Daniel, «Les plans terriers des abbayes du Pays de Caux occidental", in Les abbayes de Normandie, Actes du XIII congrès des sociétés historiques et archéologiques de Normandie, Rouen, Lecerf, 1979, p. 227-231.

FrondeVILLE (Marquis de), «L'abbaye et le port de Fécamp pendant la Guerre de Cent ans ", in L'Abbaye bénédictine de Fécamp, t. I, 1959, p. 143-149.

GAILLARD, Louis (dom), «L'origine géographique des prieurs mauristes de Fécamp au XVII siècle", in L'Abbaye bénédictine de Fécamp, t. I, 1959 , p. 219-228 et p. 399.

GAMESON, Richard, «Manuscrits normands à Exeter aux XI ${ }^{e}$ et XII ${ }^{\mathrm{e}}$ siècles», in Manuscrits et enluminures, 2005, p. 107-128.

GANZ, David, Corbie in the carolingian renaissance, Sigmaringen, Thorbecke, 1990, $192 \mathrm{p}$.

GARAND, Monique-Cécile, "Les anciennes bibliothèques du XIII ${ }^{e}$ au $\mathrm{XV}^{\mathrm{e}}$ siècle », in Histoire des bibliothèques françaises, t. I, 1989, p. 45-64.

GASNAUlT, Pierre, «Dom Anselme Le Michel et les manuscrits de l'abbaye de Cluny", Bibliothèque de l'École des Chartes, 131, 1973, p. 209 219. 
GAZEAU, Véronique, «Guillaume de Volpiano en Normandie : état des questions », Tabularia «Études», n² 2, 2002, p. 35-46.

GotTLIEB, Theodor, Über mittelalterliche Bibliotheken, Leipzig, 1890, XI-520 p. (réimpr.).

Gouttebroze, Jean-Guy, Le précieux sang de Fécamp: origine et développement d'un mythe chrétien, Paris, Champion, 2000, 109 p.

GrEeN, Judith Ann, "Fécamp et les rois anglo-normands», Tabularia «Études», n 2, 2002, p. 9-18.

GRÉMONT, Denis-Bernard, «Lectiones ad prandium à l'abbaye de Fécamp au XIII siècle», Cahiers Léopold Delisle, 20, 1971, p. 1-41.

GulLICK, Michael, "Manuscrits et copistes normands en Angleterre (XI'-XII ${ }^{e}$ siècles) », in Manuscrits et enluminures dans le monde normand ( $X^{e}-X V^{e}$ siècle), Actes du colloque de Cerisy-la-Salle (octobre 1995), Pierre Bouet et Monique Dosdat (dir.), Caen, Presses universitaires de Caen, 2005, p. 83-93.

Hagen, Hermann, Der Jurist und Philolog Peter Daniel aus Orléans, Berne, Haller, 1873, p. 1-35.

ID., Catalogus codicum Bernensium Bibliotheca Bongarsiana, Berne, Haller, $1875,662 \mathrm{p}$.

HeLlot, Amédée, Fécamp au temps de la Ligue: la légende de Boisrosé d'après des documents nouveaux, Yvetot, Bretteville, 1897, 121 p. (Gallica/BnF).

Herval, René, «Un moine de l'an mille: Guillaume de Volpiano, $1^{\text {er }}$ abbé de Fécamp (962-1031) », in L'Abbaye bénédictine de Fécamp..., t. I, 1959, p. 27-44 et p. 321-322.

Histoire des bibliothèques françaises, t. I, Les bibliothèques médiévales du VI e siècle à 1530, André VERNET (dir.), Paris, Promodis, 1989, XXIV$463 \mathrm{p}$.

Histoire des bibliothèques françaises, t. II, Les bibliothèques sous l'Ancien Régime (1530-1789), Claude Jolly (dir.), Paris, Promodis, 1988, XV-547 p.

Histoire des bibliothèques françaises, t. III, Les bibliothèques de la Révolution et du XIXe siècle (1789-1914), Dominique VARRY (dir.), Paris, Promodis, 1991, XII-671 p.

Huisman, Gerda C., «Notes on the manuscrit tradition of Dudon of St Quentin's Gesta Normannorum», Anglo-Normand Studies, 6, 1983, 1984, p.122-135.

HUMPHREYS, Kenneth William, «Les bibliothèques des ordres mendiants», in Histoire des bibliothèques françaises, t. I, 1989, p. 125-146. 
JARRY, Louis, Une correspondance littéraire au XVI siècle: Pierre Daniel, avocat au Parlement de Paris et les érudits de son temps, Orléans, Herluison, 1876, 96 p. (Gallica/BnF).

JOASSART, Bernard, «Henschen et Papebroch en France en 1662: Savoie - Dauphiné - Normandie - Flandres ", Analecta Bollandiana, 124, 2006, p. 93-150.

LAFFITTE, Marie-Pierre, «Esquisse d'une bibliothèque médiévale: le fonds manuscrits de l'abbaye de Saint-Thierry» in Saint-Thierry: une abbaye du VI ${ }^{e}$ au $X X^{e}$ siècle, Actes du colloque international d'histoire monastique (Reims-Saint-Thierry, 11 au 14 octobre 1976), Saint-Thierry, Association des Amis de l'Abbaye de Saint-Thierry, 1979, p. 73-100.

ID., "Les manuscrits de la collection de Thou », in Histoire des bibliothèques françaises, t. II, 1988, p. 108-109.

ID., "Les manuscrits normands de Colbert: reliures cisterciennes ", in Manuscrit et enluminures, 2005, p. 197-205.

ID., «Une acquisition de la bibliothèque du roi au XVII e siècle : les manuscrits de la famille Hurault », Bulletin du Bibliophile, à paraître.

LANGFELD, Brigitte, «Regula canonicorum or Regula monasterialis vitæ? The rule of Chrodegang and Archbishop Wulfred's reforms at Canterbury», Anglo Saxon England, 25, 1996, p. 21-36.

ID., The Old English version of the enlarged rule of Chrodegang, Frankfurt am Main, Peter Lang, 2003, p. 37-39.

LAUER, Philippe, "Le manuscrit des Annales de Flodoard Reg. Lat. 633 du Vatican ", Mélanges d'Archéologie et d'Histoire, 48, 1898, p. 491523 (Persée).

Le livre au Moyen Âge, Jean GLENISSON (dir.), Paris, CNRS Éditions, 2002, $247 \mathrm{p}$.

LE MAHO, Jacques, «La dispersion des bibliothèques du diocèse de Rouen au temps des invasions normandes: autour d'un manuscrit carolingien anciennement conservé à la Sainte-Trinité de Fécamp ", Tabularia "Études», n 4, 2004, p. 61-78.

Le Pesant, Michel, «Les relations du Mont Saint-Michel avec les autres abbayes normandes ", in Millénaire monastique du Mont Saint-Michel, t. I, Raymonde Foreville (dir.), Paris, Lethielleux, 1967, p. 743-750.

LECLERCQ, Jean (dom) et BONNES, Jean-Paul, Un maître de la vie spirituelle au XI' siècle: Jean de Fécamp, Paris, J. Vrin, 1946, 237 p. 
LECLERCQ, Jean (dom), «Prières d'apologie dans un Sacramentaire du Mont Saint-Michel: Jean de Fécamp au Mont Saint-Michel », in Millénaire monastique du Mont Saint-Michel, t. II, Raymonde ForEVILLE (dir.), Paris, Lethielleux, 1967, p. 357-361.

LECROQ, Gaston (dom), «Les manuscrits liturgiques de l'abbaye de Fécamp », Fécamp, 1935, 64 p. (extrait du Bulletin de l'Association des Amis du Vieux-Fécamp de 1934).

LEROQUAIS, Victor, Les sacramentaires et les missels manuscrits des bibliothèques publiques de France, Paris, t. I, 1924, p. 194-196, t. II, 1924, p. 153 et $377-378$, t. III, 1924, p.159-160 et 258-259, t. IV, 1934, p. $94-96$.

LESNE, Émile, Histoire de la propriété ecclésiastique en France, t. IV, Les livres "scriptoria" et bibliothèques du commencement du VIII à la fin du XI ${ }^{e}$ siècle, Lille, Facultés catholiques, 1938 (réimpr. 1964), VIII$852 \mathrm{p}$.

LETHÈVE, Jacques, «Les représentations de l'abbaye de Fécamp au cabinet des estampes de la Bibliothèque nationale ", in L'Abbaye bénédictine de Fécamp. Ouvrage scientifique du XIII centenaire (6581958), t. III, Jehan Le Povremoyne (dir.), Fécamp, L. Durand et fils, 1961, p. 129-132 et 267.

Lire le manuscrit médiéval, Paul GÉHIN (dir.), Paris, Armand Colin, 2005, 282 p.

Lumières de l'an mil en Orléanais, autour du millénaire d'Abbon de Fleury, Aurélie Bosc et Annick NotTer (éd.), Turnhout, Brepols, 2004, 380 p.

MAILlard, Jean-François, "Postel et ses disciples normands», in Guillaume Postel: 1581-1981, Actes du Colloque International d'Avranches (5-9 septembre 1981), Paris, Éd. de la Maisnie, 1985, p. 79-94.

Mandragore, base de données iconographiques de la BnF: http://mandragore.bnf.fr/html/accueil.html

Les manuscrits classiques latins de la Bibliothèque Vaticane, Elisabeth PELLEGRIN (dir.), t. I-II, Paris, CNRS Éditions, 1975-1978, 843+526 p.

Manuscrits et enluminures dans le monde normand ( $X^{e}-X V^{e}$ siècle), Actes du colloque de Cerisy-la-Salle (octobre 1995), Pierre BouET et Monique Dosdat (dir.), Caen, Presses universitaires de Caen, 2005, 227 p.

MAthan, B. (de) (abbé), «L'abbaye de Fécamp dans les cahiers de dom Lenoir ", in L'Abbaye bénédictine de Fécamp, t. II, 1960, p. 255-274 et p. 387 . 
MECH, Paul, «Les bibliothèques de la Compagnie de Jésus », in Histoire des bibliothèques françaises, t. II, 1988, p. 57-63.

Mellot, Jean-Dominique, «Rouen au XVII e siècle», in Histoire des bibliothèques françaises, t. II, 1988, p. 455-466.

MÉRIAUX, Charles, «Thérouanne et son diocèse jusqu'à la fin de l'époque carolingienne », Bibliothèque de l'École des Chartes, 158, 2001, p. 377-406.

Meyier, Karel Adriaan (de), Paul en Alexandre Petau en de geschiedenis van hun handschriften (voornarmelijk op grond van de Petau-handschriften in de universiteitsbibliotheek te leiden), Leyde, E. J. Brill, 1947, $238 \mathrm{p}$.

MOLINIER, Auguste, Catalogue des manuscrits de la Bibliothèque Mazarine, t. I, Paris, Plon, 1885, XXVIII-530 p.

MONTFAUCON, Bernard (de), Bibliotheca bibliothecarum manuscriptorum nova, t. II, Paris, Briasson, 1739.

MONTIER, Jean, «L'abbaye de la Sainte-Trinité de Fécamp au XVIII e siècle», in L'Abbaye bénédictine de Fécamp, t. II, 1960, p. 17-96 et p. 325-349.

ID., «Les moines de Fécamp pendant la Révolution », in L'Abbaye bénédictine de Fécamp, t. III, 1961, p. 133-222 et p. 269-300.

MOSTERT, Marco, The Library of Fleury: a provisional list of manuscript, Hilversum (Middeleeuwse studies en bronnen, 3), 1989, 315 p.

Munby, Alan Noel Latimer, Phillipps Studies, Cambridge, University Press, t. III, The Formation of the Phillipps Library up to the Year 1840, 1954, p. 19-41, t. V, The Dispersal of the Phillipps Library, 1960, p. 22-50.

MUSSET, Lucien, «La contribution de Fécamp à la reconquête monastique de la Basse-Normandie ", in L'Abbaye bénédictine de Fécamp, t. I, 1959, p. 57-66 et p. 341-343.

ID., «La vie économique de l'abbaye de Fécamp sous l'abbatiat de Jean de Ravenne", in L'Abbaye bénédictine de Fécamp, t. I, 1959, p. 67-79 et p. 345-349.

Munk Olsen, Birger, «Les bibliothèques bénédictines et les bibliothèques de cathédrales: les mutations des $\mathrm{XI}^{\mathrm{e}}$ et $\mathrm{XII}^{\mathrm{e}}$ siècles ", in Histoire des bibliothèques Françaises, t. I, 1989, p. 31-44.

ID. \& Petitmengin, Pierre, «Les bibliothèques et la transmission des textes ", in Histoire des bibliothèques françaises, t. I, 1989, p. 415-435.

NORTIER [-MARCHAND], Geneviève, Les bibliothèques médiévales des abbayes de Normandie, thèse de l'École des Chartes, Paris, 1953 (résumé dans École des chartes, Positions des thèses, 1953). 
ID. «Les bibliothèques médiévales des abbayes de Normandie», Revue Mabillon, $\mathrm{n}^{\circ} 187-190,1957$, p. $1-33,57-83,135-171$ et 219-244; $\mathrm{n}^{\circ} 191-194$, 1958 , p. 1-19, 99-127, 165-175 et $249-257$; n 202,1960 , p. 228-241; n 206,1961 , p. 332-346; n’ 208-209, 1962, p. 118-133 (sur Fécamp, voir en particulier n ${ }^{\circ} 187,1957$, p. 6-33).

ID., «La bibliothèque de Fécamp au Moyen Âge », in L'Abbaye bénédictine de Fécamp, t. II, Jehan Le POVREMOYNe, 1960, p. 221-237 et p. 381.

ID., Les bibliothèques médiévales des abbayes de Normandie, Caen, Caron, 1966, 252 p., en particulier p. 13-33 et supplément p. 237-240 ( $2^{\mathrm{e} e ́ d .,}$ Paris, Lethielleux, 1971).

NORTIER, Michel, «Documents de la bibliothèque nationale de Paris relatifs à Fécamp ", in L'Abbaye bénédictine de Fécamp, t. II, 1960, p. 245254 et p. 383-385.

ID., «Les sources de l'histoire de la Normandie (et du monachisme normand en particulier) à la bibliothèque nationale », in Aspect du monachisme en Normandie (IV $V^{e} X V I I I^{e}$ siècles), Actes du Colloque Scientifique de l'«Année des Abbayes Normandes» (Caen, 18-20 octobre 1979), Lucien MusSET (dir.), Paris, J. Vrin, 1982, p. 159-183.

OMONT, Henri, "Catalogue des manuscrits de la bibliothèque de Cujas (1574)", Nouvelle Revue Historique de Droit Français et Étranger, année IX, 1885, p. 233-237 (Gallica/BnF).

ID., "Inventaire des manuscrits de la bibliothèque de Cujas (1590) », Nouvelle Revue Historique de Droit Français et Étranger, année XII, 1888, p. 632-641 (Gallica/BnF).

ID., Catalogue général des manuscrits des bibliothèques publiques de France, t. I-II, Paris, Plon, 1886-1888.

ID., Inventaire de la collection Moreau, Paris, Picard, 1891, IV-282 p.

ID., Concordances des numéros anciens et des numéros actuels des manuscrits latins de la Bibliothèque nationale, Paris, Leroux, 1903.

ID., Catalogue des manuscrits latins et français de la collection Phillipps acquis en 1908 pour la Bibliothèque nationale, Paris, Leroux, 1909.

ID., Anciens inventaires et catalogues de la Bibliothèque nationale, t. IV, Paris, Leroux, 1913.

ID., Nouvelles acquisitions du département des manuscrits pendant les années 1921-1923, Paris, Leroux, 1924.

ID., "Cartulaire-obituaire de la Pitancerie de l'abbaye de Fécamp au XIII siècle», Mélanges de la Société de l'histoire de Normandie, 9 série, 1925, p. 269-280.

OuY, Gilbert, «Saint-Victor de Paris », in Histoire des bibliothèques françaises, t. I, 1989, p. 86-89. 
PALLIER, Denis, «Les conséquences des guerres de Religion », in Histoire des bibliothèques françaises, t. II, 1988, p. 15.

Patrimoine des bibliothèques de France, vol. 9, Haute et Basse-Normandie, Paris, Payot, 1995, 191 p.

Pellegrin, Elisabeth, «Manuscrits de l'abbaye de Saint-Victor et d'anciens collèges de Paris à la Bibliothèque municipale de Berne, à la Bibliothèque Vaticane et à Paris ", Bibliothèque de l'École des Chartes, 103, 1942, p. 69-98.

ID., «Membra disjecta », Bibliothèque de l'École des Chartes, 107, 19471948, p. 74-76.

ID., «Les manuscrits de Loup de Ferrières. À propos du ms. Orléans 162 (139) corrigé de sa main », Bibliothèque de l'École des Chartes, 115, 1957, p. 5-31.

ID., «Membra disiecta Floriacensia », Bibliothèque de l'École des Chartes, 117,1959 , p. 5-56.

ID., « Notes sur quelques recueils de vies de saints utilisés pour la liturgie à Fleury-sur-Loire au XI ${ }^{\mathrm{e}}$ siècle ", Bulletin d'information de l'Institut de Recherche et d'Histoire des Textes, 12, 1963, p. 7-30.

ID., «Possesseurs français et italiens de manuscrits latins au fonds de la Reine à la Bibliothèque Vaticane », Revue d'Histoire des Textes, 3, 1973, p. 271-297.

ID., «Le manuscrit Paris Bibl. nat. 2389 et ses "membra disiecta” ", Revue d'Histoire des Textes, 8, 1978, p. 295-302.

ID., «Membra disiecta Floriacensia (II)», in Miscellanea codicologica F. Masai dicata, Gand, E. Story-Scientia, 1979, p. 83-103.

ID., « Fragments et membra disiecta », Codicologica, 3, 1980, p. 70-95.

ID., «La tradition des textes classiques latins à l'abbaye de Fleury-surLoire», Revue d'Histoire des Textes, 14-15, 1984-1985, p. 155-167.

ID., «Nouveaux fragments du lectionnaire hagiographique de Fleury: Paris, Bibl. nat. 12606 », Scriptorium, 39, 1985, p. 269-274.

ID., Bibliothèques retrouvées: manuscrits, bibliothèques et bibliophiles du Moyen Âge et de la Renaissance, Paris, CNRS Éditions, 1990, 568 p.

Petitmengin, Pierre, «Montfaucon, dom Le Maître et la Bibliotheca bibliothecarum ", in Du copiste au collectionneur. Mélanges d'histoire des textes et des bibliothèques en l'honneur d'André Vernet, textes réunis par Donatella NEBBIAI-DALLA GUARDA et Jean-François GENEST, Turnhout, Brepols, 1998 (Bibliologia, 18), p. 537-584. 
Peyrafort-Huin, Monique, La bibliothèque médiévale de l'abbaye de Pontigny (XII ${ }^{e}-X I X^{e}$ siècles): histoire, inventaires anciens, manuscrits, Paris, CNRS Éditions, 2001, 846 p.

Platelle, Henri (abbé), «La place de l'abbaye de Fécamp parmi les sociétés de prières de l'abbaye de Saint-Amand", in L'Abbaye bénédictine de Fécamp, t. I, 1959, p. 137-141 et p. 379-380.

POTTS, Cassandra W., «Les ducs normands et leurs nobles: le patronage monastique avant la conquête de l'Angleterre", Études normandes, $35,3,1986$, p. 29-37.

Recueil des actes des ducs de Normandie de 911 à 1066, Marie FAUroux (éd.), Caen, Société des antiquaires de Normandie, 1961, 560 p.

RenouX, Annie, «Le monastère de Fécamp pendant le Haut Moyen Âge (VII ${ }^{e}-\mathrm{IX}^{e}$ siècle) : quelques données historiques et archéologiques ", in Les abbayes de Normandie, Actes du XIII ${ }^{\mathrm{e}}$ congrès des sociétés historiques et archéologiques de Normandie, Rouen, Lecerf, 1979, p. 116-132.

ID., Fécamp: du palais ducal au palais de Dieu, bilan historique et archéologique des recherches menées sur le site du château des ducs de Normandie, Paris, CNRS Éditions, 1991, 734 p.

Répertoire des cartulaires médiévaux et modernes (CartulR), Paul BERTRAND (éd.), Orléans, Institut de Recherche et d'Histoire des Textes, 2006 (Ædilis, Publications scientifiques, 3) : http://www.cn-telma.fr/ cartulR/

RichARD, Hélène, «Des bibliothèques des districts aux bibliothèques municipales ", in Histoire des bibliothèques françaises, t. III, 1991, p. 43-59.

RoNZY, Pierre, Un humaniste italianisant: Papire Masson (1544-1611), Paris, Champion, 1924.

ROUET, Dominique, «Les livres de médecine à l'abbaye de Fécamp aux XVI ${ }^{e}-X V I I I^{e}$ siècles", in L'hôpital de Fécamp: mille ans d'histoire, Fécamp, Éditions des Falaises, 2005, p. 19-25.

ID., "Ein herrliches Präsent», Die Bongars-Bibliothek seit 350 Jahren in Bern, 1983.

SHARPE, Richard, Titulus: identifying medieval latin texts (an evidencebased approach), Turnhout, 2003, $301 \mathrm{p}$.

Simonnet, J., «Le président Fauchet, sa Vie et ses ouvrages », Revue Historique de Droit Français et Étranger, IX, 1863, p. 425-470 (Gallica/BnF). 
SinNER, J. R., Catalogus codicum manuscriptorum Bibliothecae Bernensis, Berne, 1760, 3 vol.

STEIGER (VON), Christoph, «Aus der Geschichte der Bongars-Handschriften der Burgerbibliothek Bern », Librarium, 3, 1960, p. 86-99.

Stirnemann, Patricia, «Nicolas de Montiéramey, Jean de Salisbury et deux florilèges d'auteurs antiques", in Revue d'Histoire des Textes, 1, 2006, p. 173-180,

TISCHLER, Matthias, Einharts Vita Karoli: Studien zur Entstehung, Überlieferung und Rezeption (MGH Schriften 48), Hanovre, Hahnsche Buchhandlung, 2001, 2 vol., LXXVI-1828 p.

TRÂN-DUC, Lucile, «Les princes normands et les reliques ( $\mathrm{X}^{\mathrm{e}}-\mathrm{XI}{ }^{\mathrm{e}}$ siècles): contribution du culte des saints à la formation territoriale et identitaire d'une principauté », in Reliques et sainteté dans l'espace médiéval, Jean-Luc DeufFIC (dir.), Saint-Denis, Pecia, 2006, p. 525-561.

VARRY, Dominique, "Les confiscations révolutionnaires », in Histoire des bibliothèques françaises, t. III, 1991, p. 9-27.

VAN HouTs, Elisabeth, The gesta Normannorum ducum of William of Jumièges, Orderic Vitalis, and Robert of Torigni, Oxford, Clarendon Press, 1992-1995, 2 vol., CXXXIII-156 + XV-341 p.

VEZIN, Jean, Les scriptoria d'Angers au XIe siècle, Paris, Champion, 1974, $347 \mathrm{p}$.

VIDIER, Alexandre, L'historiographie à Saint-Benoît-sur-Loire et les miracles de Saint-Benoît, Paris, Picard, 1965, 313 p.

Viola, C., "Aristote au Mont Saint-Michel», in Millénaire monastique du Mont Saint-Michel, t. II, Raymonde Foreville (dir.), Paris, Lethielleux, 1967, p. 289-312.

WebBer, Teresa, «Les manuscrits de Christ Church (Cantorbéry) et de Salisbury», in Manuscrits et enluminures, 2005, p. 95-106.

WiLmart (dom), André, Bibliothecae Apostolicae Vaticanae, codices Reginenses latini, t. I-II, Vatican, Bibliotheca Vaticana, 1937-1945, xviii$846+$ viii-992 p.

ZuRfluh, Pierre, "L'héraldique des abbés de Fécamp », in L'Abbaye bénédictine de Fécamp, t. II, 1960, p. 275-294. 


\section{Annexes}

Diagramme 1 : dispersions attestées

et hypothèses de dispersion des manuscrits de La Trinité de Fécamp

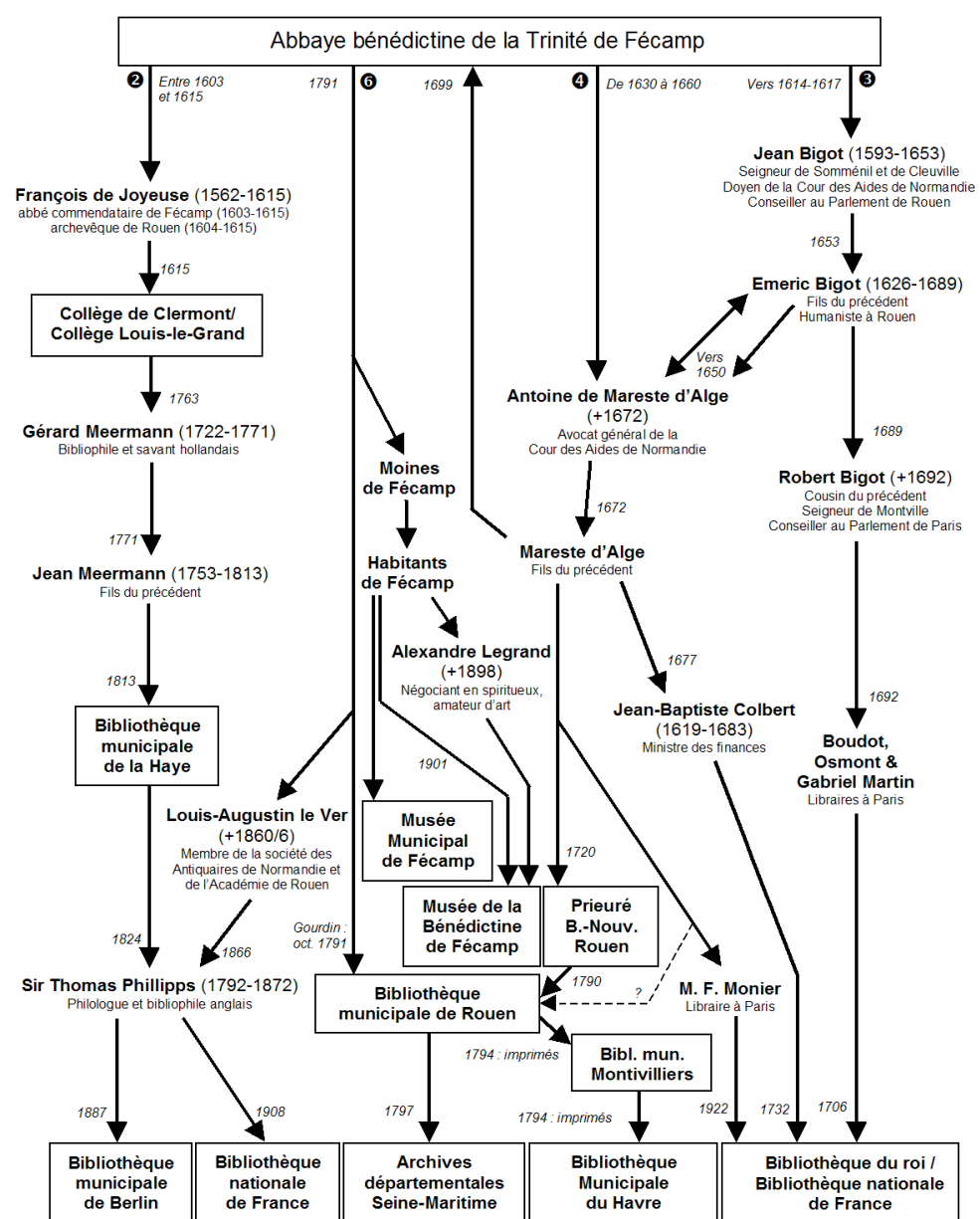




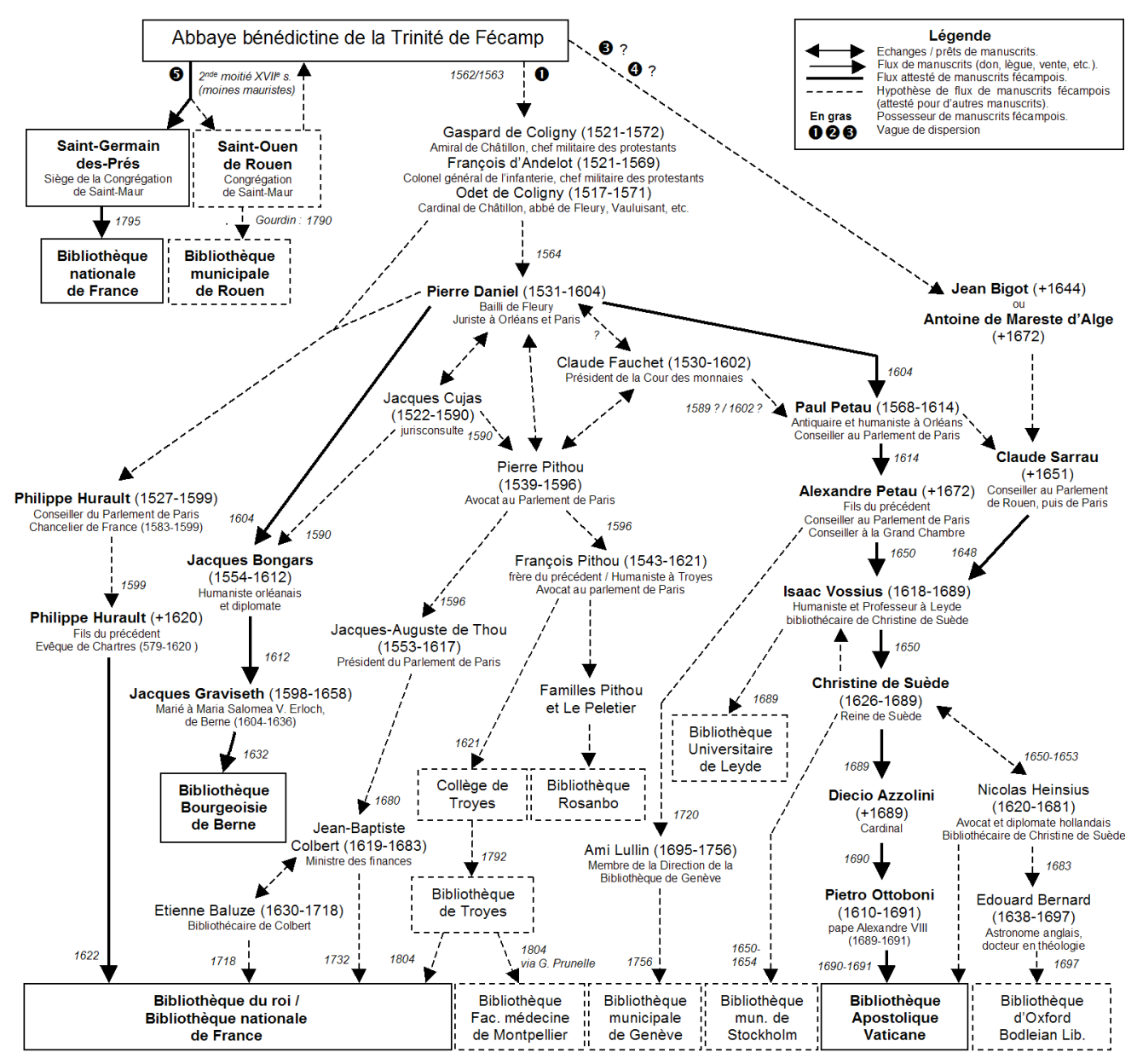




\section{Liste provisoire des manuscrits latins de La Trinité de Fécamp ${ }^{156}$}

\begin{tabular}{|c|c|c|}
\hline Bibliothèque & Possesseurs & Liste des manuscrits de Fécamp \\
\hline \multirow[t]{3}{*}{$\begin{array}{l}\text { Bibliothèque } \\
\text { municipale de } \\
\text { Rouen } \\
\text { (114 à } 120 \text { mss) }\end{array}$} & Gourdin (92 à $96 \mathrm{mss}$ ) & $\begin{array}{l}1,7,25,28,29,30,41,79,86,98,106,116,118,130,131,133, \\
142,143,145,205,206,223,237,238,244,245,251,253, \\
265 ?, 290,292,293,294,295,313,424,429,437,44,445, \\
448,451,464,465,469,471,477,478,489,491,492,524,526, \\
532,555,560,561,563,571,572,585,601 ?, 604,609,613, \\
626,647,673 ?, 676,709,714,720,721,730,738,755,756 ?, \\
920,922,923,924,934,978,980,983,984,1027,1029,1122, \\
1208,1325,1388,1400,1415,1417,1470\end{array}$ \\
\hline & \begin{tabular}{|l|} 
Gourdin ? Mareste? \\
St-Ouen? (8 a 9 mss)
\end{tabular} & $42,348,350,452,540,612 ?, 1028,1207,1342$ \\
\hline & \begin{tabular}{|l|} 
Mareste (10 à 11 mss) \\
Bigot/Mareste $(4 \mathrm{~ms})$ \\
\end{tabular} & $\begin{array}{l}243,284,425,521,547,570,576,1042,1049,1404,[1420 ?] \\
427,525,528,1233\end{array}$ \\
\hline \multirow[t]{6}{*}{$\begin{array}{l}\text { Bibliothèque } \\
\text { nationale de } \\
\text { France, } \\
\text { fonds latin } \\
\text { ( } 67 \text { à } 78 \text { mss) }\end{array}$} & \begin{tabular}{|l|l|} 
Bigot (52 mss) \\
\end{tabular} & 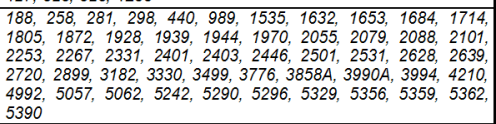 \\
\hline & $\begin{array}{l}\begin{array}{l}\text { Mareste/Colbert } \\
(7 \mathrm{à} 18 \mathrm{mss})\end{array} \\
\end{array}$ & $\begin{array}{l}63 ?, 99 ?, 123 ?, 310 ?, 437,691 ?, 708,1736 ?, 1843,1916 ? \\
1992,1997 ?, 2019 ?, 2405,2801 ?, 2914 ?, 5080,5305\end{array}$ \\
\hline & Hurault & 564 \\
\hline & \begin{tabular}{|l|} 
St-Germain-des-Prés \\
$(5 \mathrm{mss})$
\end{tabular} & $\begin{array}{l}11645 \text { (fol. } 227-228 \text { et fol. 351-352), } 11814 \text { (fol. 209-211), } 11820 \\
\left.\left(n^{\circ} 40, n^{\circ} 57\right), 12778 \text { (fol. } 101-104\right), 13069 \text { (fol. 25-43) }\end{array}$ \\
\hline & Mareste/Monier & nouv. acq. lat. 1137 \\
\hline & Le Ver/Phillipps & nouv. acq. lat. 2412 [nouv. acq. fr. 10670 ?] \\
\hline \multirow{3}{*}{$\begin{array}{l}\text { Bénédictine de } \\
\text { Fécamp } \\
\text { (6à } 9 \mathrm{mss})\end{array}$} & Le Grand (4a $7 \mathrm{mss})$ & $196 ?, 197 ?, 198 ?, 200,201,207$ (fonds mauristes), 208 \\
\hline & & Partie de l'ancien chartrier de l'abbaye; ;ivres imprimes \\
\hline & $\begin{array}{l}\begin{array}{l}\text { Mareste/Le Grand } \\
(2 \mathrm{mss})\end{array} \\
\text {. }\end{array}$ & 186,204 \\
\hline $\begin{array}{c}\text { Archives } \\
\text { departementales } \\
\text { Seine-Maritime }\end{array}$ & Gourdin & $\begin{array}{l}\text { Partie de l'ancien chartrier de l'abbaye (fonds } 7 \mathrm{H} \text { ). } \\
\text { Plan terrier } n^{\circ} 45\end{array}$ \\
\hline \multirow{2}{*}{$\begin{array}{c}\text { Bibliotheqque } \\
\text { apostolique } \\
\text { Vaticane } \\
\text { (5mss) }\end{array}$} & Daniel/Petau (4 mss) & $\begin{array}{l}\text { Reg. lat. } 107,633 \text { (fol. 39-80), } 755 \text { (fol. 100-105) } \\
\text { Ottob. lat. } 909 \text { (fol. 1-48) }\end{array}$ \\
\hline & \begin{tabular}{|l|} 
Bigot ? Mareste ? \\
Petau? Sarrau \\
\end{tabular} & Reg. lat. 500 \\
\hline \multirow[t]{2}{*}{$\begin{array}{l}\text { Musée municipal } \\
\text { de Fécamp } \\
\text { (3 mss) }\end{array}$} & \begin{tabular}{|l|} 
Le Tellier/Robin/ \\
Biochet/Le Courtois \\
(2 mss)
\end{tabular} & 5004,5005 \\
\hline & & 21 (catalogue des livres imprimés en 1791) \\
\hline $\begin{array}{c}\text { Bibliothèque de la } \\
\text { ville de Berlin } \\
\text { (2 mss) }\end{array}$ & \begin{tabular}{|l|} 
de Joyeuse/ Collège \\
Clerm./Meermann/ \\
Phillipps $(2 \mathrm{mss})$ \\
\end{tabular} & 1696 (fol. 150-159), 1854 \\
\hline $\begin{array}{c}\text { Burgerbibliothek } \\
\text { de Berne }\end{array}$ & Danie//Bongars & 162 \\
\hline $\begin{array}{l}\text { Cathédrale de } \\
\text { Salisbury }\end{array}$ & & 89 \\
\hline $\begin{array}{l}\text { Bibliothèque } \\
\text { municipale de } \\
\text { Montivilliers }\end{array}$ & Gourdin & 5 \\
\hline $\begin{array}{c}\text { Bibliothèque } \\
\text { municipale du } \\
\text { Havre }\end{array}$ & Gourdin & $\begin{array}{l}900 \text { (catalogue des livres imprimés en } 1 \\
\text { Livres imprimés (2061 titres) }\end{array}$ \\
\hline
\end{tabular}

156. 200 à 220 manuscrits. Les mss suivis de «?» méritent une étude plus approfondie quant à l'attribution de leur origine/provenance. Les mss en italiques se sont pas référencés dans les catalogues de dom Feray/Montfaucon vers 1699. La liste des manuscrits de Fécamp conservés dans les fonds grecs et français de la BnF n'a pu être constituée à ce jour (NORTIER, 1960, p. 245-254 peut fournir une bonne base de travail). Les mss Rouen, Bibl. mun., 291, Paris, BnF, lat. 2771 et Fécamp, Musée de la Bénédictine, 187, 195, 199, 202 et 203 ne sont pas de La Trinité de Fécamp. Les mss Rouen, Bibl. mun., 243 et 284 appartiennent à Fécamp depuis 1699 (dons du fils d'Antoine de Mareste) et les ms Rouen, Bibl. mun., 576, 920, 922 et 924 depuis la fin du XV ${ }^{\mathrm{e}}$ siècle (dons en 1480 et 1499). Le fol. 19 du ms Paris, BnF, nouv. acq. lat. 239 provient du ms Rouen, Bibl. mun., 425. Le Musée de la Bénédictine de Fécamp possède, depuis 1901, un lot important de chartes, vidimus, lettres, etc. de La Trinité de Fécamp (ENGEL, 1960, p. 304-316). 